\title{
Solution combustion synthesis of highly dispersible and dispersed iridium oxide as anode catalyst in PEM water electrolysis
}

\author{
Muralidhar G. Chourashiya ${ }^{a}$ and Atsushi Urakawa ${ }^{a, *}$
}

Iridium based materials are the state-of-the-art anode catalysts for polymer electrolyte membrane (PEM) water electrolysis thanks to their unmatched stability and performance in the acidic environment of common PEMs like Nafion ${ }^{\circledR}$. However, their uses on a large-scale operation are cost-restrictive. To improve their wider utilization, identifying a synthesis method of nano-structured iridium oxide with high active surface area, possibly in a supported-form, is of great importance. For this aim, we developed a one-step and cost-effective solution combustion synthesis (SCS) method to prepare nano-structured $\mathrm{IrO}_{2}$ and $\mathrm{IrO}_{2}$-based materials suitable for PEM electrolysis. Among various materials prepared, the iridium oxide incorporated and dispersed in amorphous alumina showed high surface area (131 $\left.\mathrm{m}^{2} \mathrm{~g}^{-1}\right)$ and the current density of $1.78 \mathrm{~A} \mathrm{~cm}^{-2}$ at $1.8 \mathrm{~V}$ which is comparable to the performance of the state-of-the-art commercial MEA made of IrRuO ${ }_{x}\left(1.8 \mathrm{~A} \mathrm{~cm}^{-2}\right.$ at $1.8 \mathrm{~V}$ ) under PEM water electrolysis. Importantly, the dispersion of the material in the catalyst ink used for the preparation of membrane electrode assembly (MEA) was significantly superior compared to commercial IrO ${ }_{2}$ nanoparticles and the amount of the precious metal in the catalyst made by SCS could be reduced by 45 wt\% compared to that in the commercial MEA.

\section{Introduction}

Hydrogen has been considered as chemical energy carrier alternative to fossil fuels over the past decades. Hydrogen has the potential to provide clean, reliable and affordable energy supply to meet the growing global energy demand. ${ }^{1-3}$ Apart from being a clean fuel yielding water as only byproduct upon combustion, hydrogen can be produced using natural and renewable energies ${ }^{4}$ and then it can readily be used in fuel cells ${ }^{5-7}$ to produce clean power for variety of applications. This energy pathway could serve as one of the solutions to sustainable energy supply. Among various approaches, a promising method to produce highly pure hydrogen is by electric potential induced water splitting (water electrolysis). ${ }^{1}$ In a conceptual distributed energy production, conversion, storage and use system, e.g. for off-grid locations, water electrolysis can play pivotal roles (Section S1.1 and Figure S1, electronic supporting information - ESI). ${ }^{2}$

Two major reactions take place during electrochemical water splitting: hydrogen evolution reaction (HER) and oxygen evolution reaction (OER). Among the two, OER is considerably more energy demanding and is the major contributor to the energy losses due to the higher overpotential of OER in water electrolysis. The most active electrocatalysts known to date for $\mathrm{OER}$ are $\mathrm{IrO}_{2}$ and $\mathrm{RuO}_{2}{ }^{8-}$ ${ }^{10} \mathrm{IrO}_{2}$ exhibits high corrosion resistance with slightly less activity compared to $\mathrm{RuO}_{2} .{ }^{9}$ Furthermore, the standard amount of loading of $\mathrm{IrO}_{2}$ (or $\left(\mathrm{rRuO}_{\mathrm{x}}\right.$ ) is rather high $\left(\sim 3 \mathrm{mg} \mathrm{cm}{ }^{-2}\right.$ ), hampering the commercialization of polymer electrolyte membrane (PEM) water electrolysis on a large scale. Therefore, to enhance the activity of $\mathrm{IrO}_{2}$ and to reduce the precious metal loading (Section S1.2, ESI), synthesis of $\mathrm{IrO}_{2}$ in a nano-structured and dispersed form is of paramount importance.

Herein, we present, for the first time, a facile one-step method to synthesize nano-structured iridium oxide using solution combustion synthesis (SCS) (Sections S1.3 and S1.4, ESI). SCS is based on a highly exothermic and auto-thermal reaction and it has been used to synthesize a variety of materials including binary/complex metal oxides. ${ }^{11}{ }^{12}$ Generally, two components, metal nitrates (metal sulfates and carbonates are also employed, although nitrates are generally preferred ${ }^{13}$ ) and an organic molecule like urea and glycine, are used in SCS as precursor of metal oxides and fuel, respectively. ${ }^{14}$ In this study, we employed iridium chloride as Ir source due to scarce availability of its nitrates and, consequently, we adapted and optimized the SCS method. We successfully synthesized phase-pure and nano-structured $\mathrm{IrO}_{2}$ materials under excess of fuel (glycine) and/or by incorporation of an oxidizing additive, and further examined the effects of precursor solution composition on the structural properties of resulting $\mathrm{IrO}_{2}$ and $\mathrm{IrO}_{2}$-based materials. These materials were incorporated as anode catalyst in membrane electrode assemblies (MEAs) and their PEM water electrolysis performance was evaluated and compared with that of a state-of-the-art commercial MEA where IrRuO $\mathrm{x}$ was used as the anode catalyst.

\section{Experimental}

\section{Synthesis of iridium oxide}

First, we attempted to synthesize iridium oxide by simply mixing $\mathrm{IrCl}_{3}$ and glycine at different molar proportions (IrG series) with subsequent combustion at $400{ }^{\circ} \mathrm{C}$. Also, as the existence of nitrates in the synthesis media for SCS is of prime importance, we investigated this aspect by employing two kinds of nitrates as an additive (oxidizer), namely ammonium nitrate (IrAmG series) and aluminum nitrate (IrAIG series). In total three types of precursor compositions were investigated (Figure 1). For IrAmG series, oxidizer (ammonium nitrate) and fuel (glycine) were mixed in the stoichiometric proportion, while for IrAlG series oxidizer (aluminum nitrate) and fuel were mixed beyond the stoichiometric proportion (Sections S2.1 and S2.2, ESI). 
The resulting materials were characterized by thermal analysis, $\mathrm{N}_{2}$ physisorption, $\mathrm{X}$-ray diffraction (XRD), scanning and transmission electron microscopy (SEM/TEM). They were incorporated in MEA by spray-coating respective material at the loading of $2 \mathrm{mg} \mathrm{cm}^{-2}$ over Nafion ${ }^{\circledR} \mathrm{N}-115$ membrane $(0.125 \mu \mathrm{m}$ thick) as anode catalyst with $40 \mathrm{wt} \%$ Pt on graphitized carbon at the loading of $0.6 \mathrm{mg}$ $\mathrm{cm}^{-2}$ as cathode catalyst and further tested in water electrolysis. For comparison, the MEAs coated with commercial Ir-based materials, Ir nanopowder (iridium black, 99.8\%, Alfa Aesar) and $\mathrm{IrO}_{2}$ (99\%, Alfa Aesar) as anode catalyst were tested. Moreover, a commercial MEA coated with IrRuO (anode) and Pt (cathode) catalysts at the loading of $3 \mathrm{mg} \mathrm{cm}^{-2}$ (FuelCellEtc, USA) was also evaluated in water electrolysis. The details of the characterization methods and conditions, the MEA fabrication procedure and the electrolysis setup and parameters are described in ESI (Sections S2.3 and S2.4).

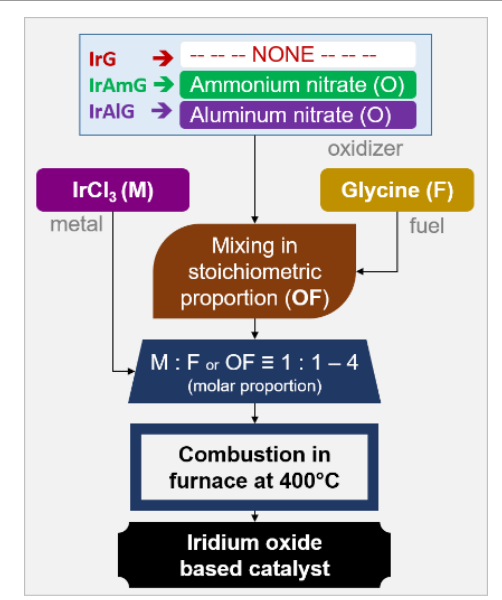

Figure 1. Flow chart for the synthesis of the iridium oxide using SCS. The molar proportion of $\mathrm{IrCl} \mathrm{B}_{3}$, oxidizer and fuel were varied (Table S1, ESI).

\section{Results and discussion}

Due to different thermal stability of the precursors, to obtain a phase-pure oxide of iridium or indium oxide after SCS, a systematic variation in their mixing proportion were evaluated (Section S3.1 and Table S1, ESI). The structures of the materials prepared by SCS were characterized by XRD and analyzed by Rietveld refinement for the identification and quantification of different phases and for their crystallite size determination (Section S3.2, ESI). For the each material series evaluated in this study, namely IrG, IrAmG or IrAIG, almost pure-phase $\mathrm{IrO}_{2}$ was obtained when the molar proportions were as follows: $\mathrm{IrCl}_{3}: \mathrm{glycine}=1: 4$ (mentioned as IrG4 in ESI); IrCl $: \mathrm{NH}_{4} \mathrm{NO}_{3}$ :glycine = 1:1:0.2 (IrAmG1 in ESI); IrCl $: \mathrm{Al}\left(\mathrm{NO}_{3}\right)_{3}$ :glycine = 1:1.4:3.5 (IrAl14G35 in ESI). Hereafter, these most phase-pure materials of the respective series will be denoted simply as IrG, IrAmG and IrAIG. In order to examine the structure and phase resulting from the $\mathrm{Al}$ component, a sample denoted as $\mathrm{AlG}$ was prepared by SCS with the same proportion of $\mathrm{Al}\left(\mathrm{NO}_{3}\right)_{3}$ and glycine (1.4:3.5) as that of IrAIG but without $\operatorname{IrCl}_{3}$. Figure 2 shows the XRD patterns of IrG, IrAmG and IrAIG in comparison to the commercial iridium oxide and commercial iridium nanopowder. The XRD pattern of AIG shows the highly amorphous nature of the material. These broad peak features almost hidden in the baseline observed for AIG and IrAIG and also further characterization using Raman spectroscopy suggest the phase of alumina to be $\gamma-\mathrm{Al}_{2} \mathrm{O}_{3}$ (Section $\mathrm{S} 3.3, \mathrm{ESI}$ ). 


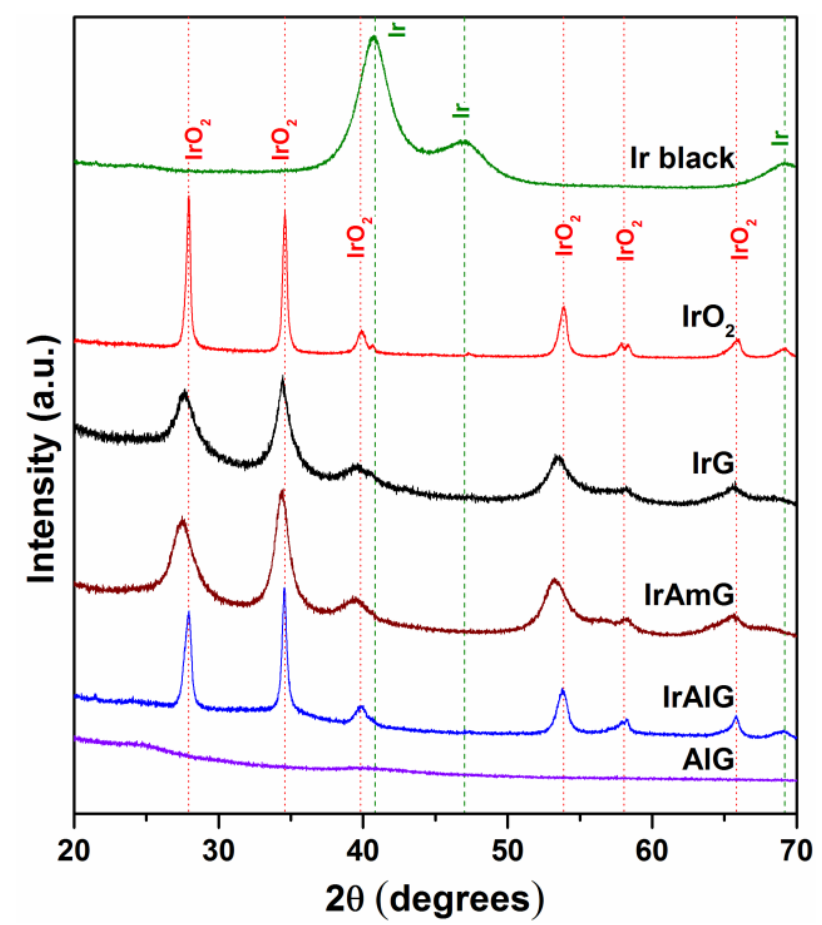

Figure 2. XRD patterns of three iridium oxide based materials (IrG, IrAmG, and IrAIG) prepared by SCS. For comparison, XRD patterns of the commercial iridium nanopowder (Ir black), the commercial iridium oxide $\left(\mathrm{IrO}_{2}\right)$ and $\mathrm{AIG}$ sample (see main text) are also presented. Vertical dotted lines correspond to peak positions of $I r \mathrm{O}_{2}$ and Ir.

The scanning electron micrographs of IrG, IrAmG and IrAIG are presented in Figure 3. The features of porous/spongy structures and rough surfaces on nanoscale were confirmed as commonly observed for materials made by SCS (Section S3.4, ESI). The morphological details are different for the three samples, but generally they consist of nano-structured needle-shaped iridium oxide particles which are the basic building block of the large agglomerates (Figure S9, ESI). The structural details of the Al containing sample, i.e. IrAIG, were strikingly different from the others. IrAIG contained needles merged through one edge to form a nano-structured agglomerate. The comparison of the micrographs of IrAIG in the secondary electron (SE) mode (Figure 3-c) and in the back-scattered electron (BSE) mode (Figure 3-d) revealed that the nano-structured needle-shaped particle, containing Ir judging from the intensity in the BSE mode, is anchored as well as embedded on/in micro-porous support presumably consisting of alumina, because the BSE mode is more sensitive to higher atomic number elements with greater sampling depth from the surface of the material. ${ }^{15}$ Curiously, energy dispersive X-ray (EDX) analysis of IrAIG at the dark spot, where the particles consisting of $\mathrm{IrO}_{2}$ needles are not present even in BSE mode, showed the presence of Ir in the region (Section S3.5, ESI). This implies that iridium is present and dispersed in some form within a matrix of alumina.
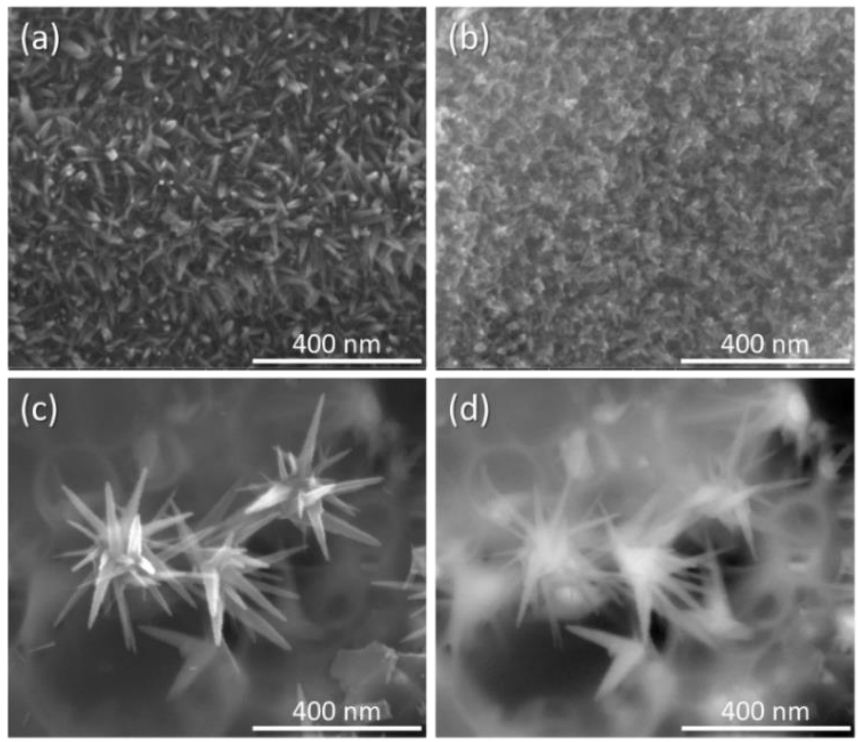

Figure 3. Scanning electron micrographs of (a) IrG, (b) IrAmG and (c) IrAIG in the secondary election (SE) detection mode. (d) shows the image in the back-scattered electron (BSE) detection mode for the same sample area of (c). 
The structural details of IrAIG sample were further investigated by TEM and EDX at high resolution. The lower magnification image (Figure 4-a) confirms the embedded nature of the agglomerated needles throughout the particle body. The high resolution EDX in the region where the needle and the supporting body are present (Figure 4-b) clearly shows that the needle contains Ir atoms but $\mathrm{Al}$ atoms are not present. In contrast, the supporting body contains both Al and Ir atoms, confirming the previous finding at lower resolution (vide supra). Furthermore, it was evidenced that the needle consists of polycrystalline $\mathrm{IrO}_{2}$ (Figure 4-c), with most of the crystal-planes oriented along (110) directions corresponding to $d$-spacing of $0.32 \pm 0.01 \mathrm{~nm}$ (Section S3.7, ESI). Interestingly, the analysis clarified that the region of the apparently-homogeneous supporting material consists of a number of highly crystalline particles with the size of 1-2 nm with homogeneous dispersion and particle size distribution (Figure 4-d). Based on the estimated $\mathrm{d}$-spacing values of those crystalline particles, it is assigned to $\mathrm{IrO}_{2}$ nanoparticles (Section S3.7, ESI). This morphology and homogeneous distribution is consistent with the above elemental analysis based on EDX.

The co-existence of nano-structured and highly dispersed $\mathrm{IrO}_{2}$ may be advantageous as it can be directly related to large active surface area in water oxidation. The textural properties of the materials made by SCS were evaluated (Section S3.6, ESI). IrAIG showed the highest surface area of $131 \mathrm{~m}^{2} \mathrm{~g}^{-1}$ among all materials. It is important to note that IrAlG was the only material which showed microporosity with the micropore surface area of $86 \mathrm{~m}^{2} \mathrm{~g}^{-1}$. IrG and IrAmG also showed higher surface area (89 and $80 \mathrm{~m}^{2}$ $\mathrm{g}^{-1}$, respectively) than the commercial Ir nanopowder $\left(52 \mathrm{~m}^{2} \mathrm{~g}^{-1}\right)$. The influence of the textural properties and unique morphologies of the materials made by SCS are further examined in water electrolysis.

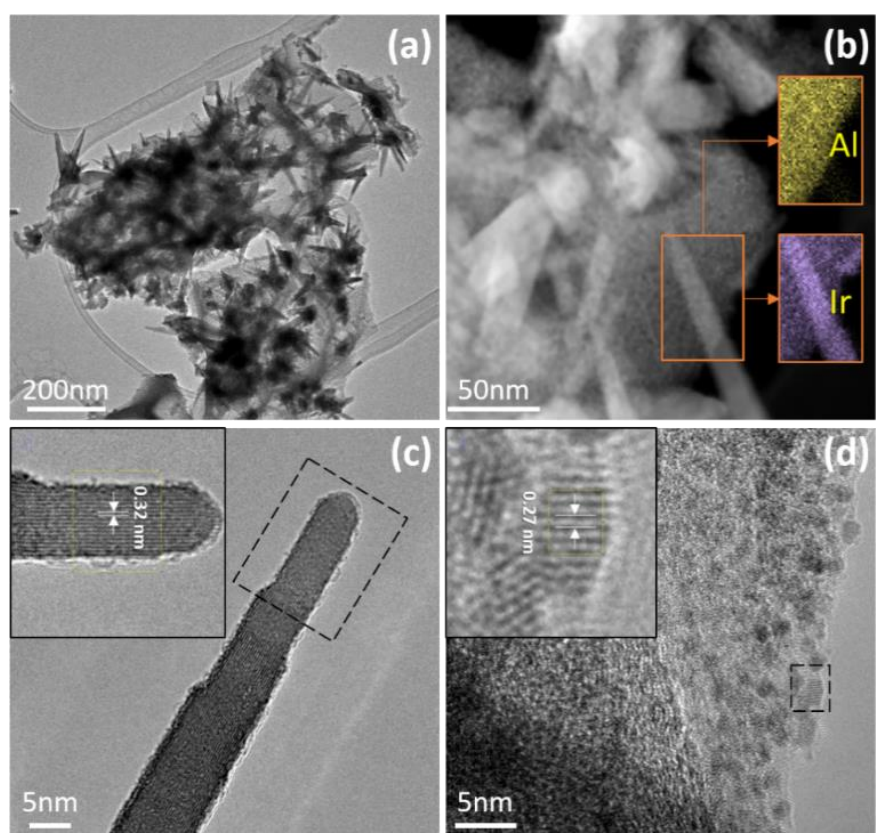

Figure 4. Transmission electron micrographs of IrAIG at (a) lower magnification, (b) high resolution EDX map showing the distribution of Al and Ir elements in the selected region, transmission electron micrographs at high resolution (c) at the head of the needle and (d) at the region where the particles consisting of the needles is not present.

For the fabrication of MEAs, the catalyst materials were spray-coated over solid electrolyte (here Nafion ${ }^{\circledR}$ ) membrane and it is of great importance to well disperse the catalyst particles in a solution and keep them suspended in ink during the coating process. During the ink preparation, we noticed that the materials made by SCS were all well-dispersed readily and stably. This could be confirmed by the TEM analysis after dispersing the materials in a solution of isopropanol upon ultra-sonication of five minutes only (Section S3.8, ESI). In contrast, upon the same treatment, the commercial iridium nanopowder (Section S3.8, ESI) showed ca. 0.5$1 \mu \mathrm{m}$ spherical particles of agglomerated nano-spheres of ca. $4 \mathrm{~nm}$, resulting in a difficulty to achieve homogeneous particle dispersion in the ink even after a long ultra-sonication treatment. This ease in dispersing the materials made by SCS is helpful to reproduce the same MEA quality and thus electrolysis performance, which had been a long-standing issue for us using the commercial Ir nanopowders.

The MEA showing large electrolysis current at lower potential without any side reactions is considered performing the best. To rule out the possibility of any side reactions in the employed electrolyzer, we first investigated the relation between the current density and the amount of hydrogen collected at the cathode outlet. On average, $1 \mathrm{~A}$ of current passing through electrolyzer produced $7.0 \pm 0.1 \% \mathrm{~N} \mathrm{ml} \mathrm{min}{ }^{-1}$ of hydrogen, which matches with the theoretical estimation of hydrogen production amount for an electrochemical water splitting reaction, confirming that water splitting is the only quantifiable reaction during electrolysis. Figure 5 shows the polarization curves under water electrolysis (Section S2.4, ESI) using Ir black, IrG, IrAmG, and IrAIG as anode catalyst and $40 \mathrm{wt} \% \mathrm{Pt} /$ carbon as cathode catalyst. For comparison, the electrolysis performance of the commercial MEA was 
measured under the same condition and shown in the same figure. The electrolysis performance with Ir black was the poorest $\left(0.17 \mathrm{~A} \mathrm{~cm}^{-2}\right.$ at $\left.1.8 \mathrm{~V}\right)$ while it was improved with IrAmG $\left(0.30 \mathrm{~A} \mathrm{~cm}^{-2}\right.$ at $\left.1.8 \mathrm{~V}\right)$ and $\operatorname{IrG}\left(0.35 \mathrm{~A} \mathrm{~cm}^{-2}\right.$ at $\left.1.8 \mathrm{~V}\right)$ in the order of the surface area (Table S2, ESI). Clearly, the electrolysis performance with IrAIG was outstanding $\left(1.78 \mathrm{~A} \mathrm{~cm}^{-2}\right.$ at $\left.1.8 \mathrm{~V}\right)$ and comparable to that of the state-of-the-art commercial MEA with IrRuO ${ }_{x}$ as anode catalyst $\left(1.80 \mathrm{~A} \mathrm{~cm}^{-2}\right.$ at $\left.1.8 \mathrm{~V}\right)$. It is worth noting that the loading of the anode catalyst in the fabricated MEAs investigated here was $2 \mathrm{mg} \mathrm{cm}^{-2}$, which is lower than that of the commercial MEA (3 $\mathrm{mg} \mathrm{cm}^{-2}$, IrRuO $_{x}$ ).

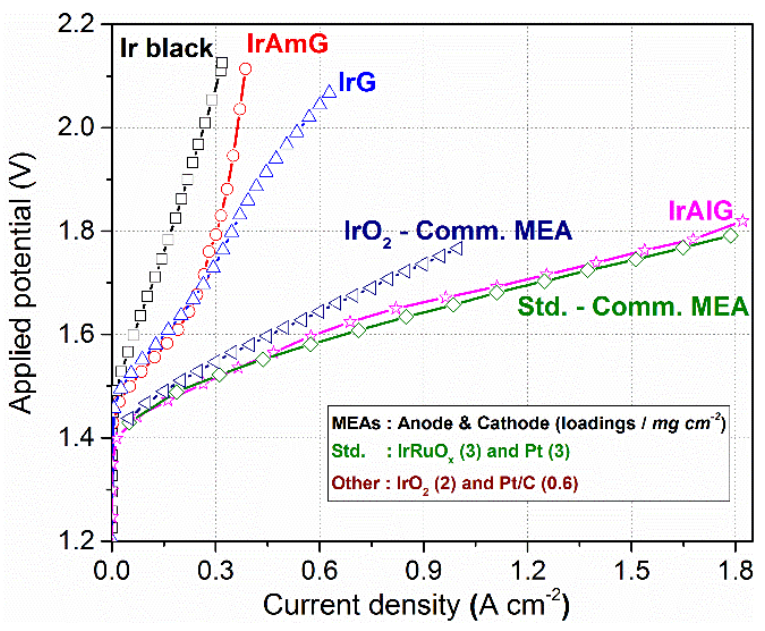

Figure 5. Polarization curves obtained in water electrolysis with MEA fabricated with the iridium oxides made by SCS (IrG, IrAmG and IrAIG) and the commercial iridium oxide and iridium nanopowder (Ir black) as anode catalysts. For comparison, a polarization curve obtained with a commercial MEA (FuelCellEtc, USA) measure d in same electrolyzer is also shown.

Furthermore, IrAIG contains $17.3 \mathrm{wt} \%$ alumina, meaning that the actual active catalyst loading employed is in fact $1.65 \mathrm{mg} \mathrm{cm}^{-2}$ for IrAIG and that about $45 \mathrm{wt} \%$ of the precious metals are saved. It is not intuitive and rather surprising that the incorporation of the well-known electrical insulator, $\mathrm{Al}_{2} \mathrm{O}_{3}$, can have a great positive impact on the electrolysis performance with a long term stability (Sections S2.2 and S3.9, ESI). This positive influence may be arising from the unique nano-structure of IrO $\mathrm{I}_{2}$ forming the particles consisting of nanoneedles and also from the high dispersion of small $\mathrm{IrO}_{2}$ nanoparticles in the alumina matrix, enhancing active surface area of $\mathrm{IrO}_{2}$ and also enabling the material electrically more conducting. Besides, the high microporosity of alumina can be beneficial to access embedded active $\mathrm{IrO}_{2}$ surfaces dispersed in the alumina structure.

\section{Conclusions}

In summary, nano-structured iridium oxides were successfully synthesized using the SCS method, with iridium chloride as metal precursor and glycine as combustion fuel. By varying the preparative parameters in SCS and the type of nitrate-additives, phasepure iridium oxide was obtained in unsupported forms as well as in a supported form within the matrix of $\mathrm{Al}_{2} \mathrm{O}_{3}$. SCS afforded obtaining nano-crystallites of iridium oxide, ranging from $3.5 \mathrm{~nm}$ to $12 \mathrm{~nm}$, with elongated-triangle/needle shaped nano-particles. With aluminum nitrate as the nitrate precursor, alumina-supported phase-pure iridium oxide (IrAIG) was obtained and it exhibited a particular structure with a one-edge-merging of iridium oxide nano-needles and nanoparticles highly dispersed within alumina matrix. Besides the advantage of ease in dispersing the SCS-made materials to prepare catalyst inks, the unique material morphology of IrAIG afforded an outstanding electrolysis performance at the same level as that of the state-of-the-art, commercial $\mathrm{IrRuO}_{\mathrm{x}}$ catalyst with a significant reduction in the use of precious metals by $45 \mathrm{wt} \%$. This study evidently shows the usefulness of the SCS method by simplicity (one-step synthesis), facile MEA preparation and outstanding performance as anode catalysts, opening new opportunities to facilitate the development of hydrogen production by water electrolysis.

\section{Acknowledgements}

We acknowledge the fellowship received under the ICIQ-IPM Programme partially funded by the Marie Curie Co-funding of Regional, National and International Programme (COFUND) action of the European Commission. We thank Generalitat de Catalunya for financial support through CERCA Programme and recognition (2014 SGR 893) and thank MINECO (CTQ2012-34153, CTQ2016-75499-R (FEDER UE)) for financial support and support through Severo Ochoa Excellence Accreditation 2014-2018 (SEV2013-0319). We thank Dr. Belén Pérez and Dr. Marcos Iglesias from Institut Català de Nanociència i Nanotecnologia (ICN2), Barcelona for timely support in SEM/TEM/STEM and EDX measurements. 


\section{References}

1 J. Suntivich, K. J. May, H. A. Gasteiger, J. B. Goodenough and Y. Shao-Horn, Science, 2011, 334, 1383-1385.

2 K. Zeng and D. Zhang, Prog. Energy Combust. Sci., 2010, 36, 307-326.

3 J. M. Ogden, Phys. Today, 2002, 55, 69-75.

4 H. Wang, D. Y. C. Leung and J. Xuan, Int. J. Hydrogen Energy, 2012, 37, 10002-10009.

5 S. A. Grigoriev, V. I. Porembsky and V. N. Fateev, Int. J. Hydrogen Energy, 2006, 31, 171-175.

6 M. Granovskii, I. Dincer and M. A. Rosen, J. Power Sources, 2006, 157, 411-421.

7 W. Kreuter and H. Hofmann, Int. J. Hydrogen Energy, 1998, 23, 661-666.

8 S. Song, H. Zhang, X. Ma, Z. Shao, R. T. Baker and B. Yi, Int. J. Hydrogen Energy, 2008, 33, 4955-4961.

9 J.-M. Hu, J.-Q. Zhang and C.-N. Cao, Int. J. Hydrogen Energy, 2004, 29, 791-797.

10 E. Rasten, G. Hagen and R. Tunold, Electrochim. Acta, 2003, 48, 3945-3952.

11 A. S. Mukasyan and P. Dinka, Int. J. Self-Propag. High-Temp Synth., 2007, 16, 23-35.

12 S. T. Aruna and A. S. Mukasyan, Curr. Opin. Solid State Mater. Sci., 2008, 12, 44-50.

13 J. Zhang, Q. Guo, Y. Liu and Y. Cheng, Industrial \& Engineering Chemistry Research, 2012, 51, 12773-12781.

14 K. Rajeshwar and N. R. de Tacconi, Chem. Soc. Rev., 2009, 38, 1984-1998.

15 J. Goldstein, D. E. Newbury, D. C. Joy, C. E. Lyman, P. Echlin, E. Lifshin, L. Sawyer and J. R. Michael, Scanning Electron Microscopy and X-ray Microanalysis: Third Edition, Springer US, 2012. 


\title{
Electronic Supplementary Information (ESI)
}

\section{Solution combustion synthesis of highly dispersible and dispersed iridium oxide as anode catalyst in PEM water electrolysis}

\author{
Muralidhar G. Chourashiya and Atsushi Urakawa*
}

Institute of Chemical Research of Catalonia (ICIQ), The Barcelona Institute of Science and Technology (BIST), Av. Països Catalans 16, 43007 Tarragona, Spain.

* Corresponding author: aurakawa@iciq.es 


\section{S1. Introduction}

\section{S1.1. Water electrolysis playing crucial role in conceptual distributed energy production}

In a conceptual distributed energy production, conversion, storage and use system, e.g. for off-grid locations, the water electrolysis can play an important role (Figure S1) ${ }^{1}$.

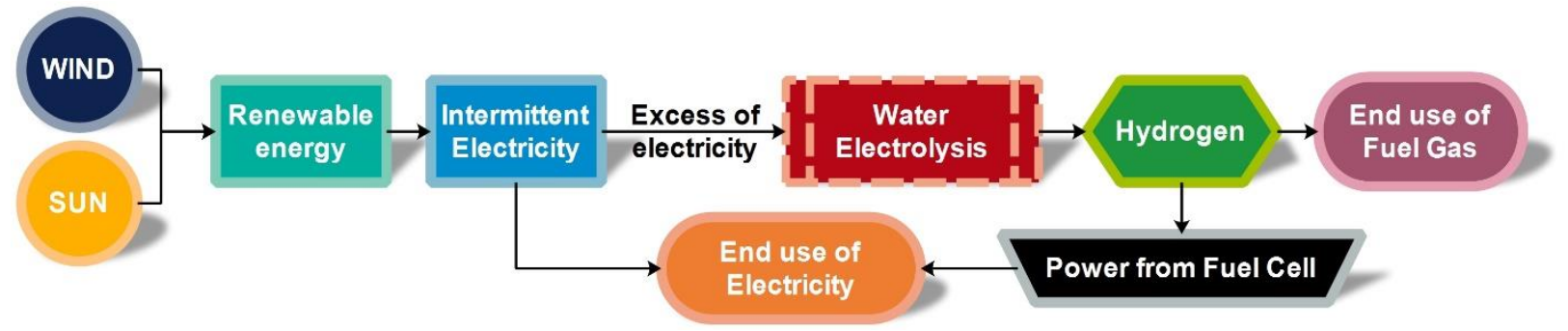

Figure S1. Schematic illustration of a conceptual distributed energy system with water electrolysis playing an important role in hydrogen production as a fuel gas and energy storage mechanism. ${ }^{1}$

\section{S1.2. Bottleneck for the $\mathrm{IrO}_{2}$ or IrO $\mathrm{I}_{2}$-based catalysts in PEM water electrolysis and its resolution}

The major bottleneck for the $\mathrm{IrO}_{2}$ or $\mathrm{IrO}_{2}$-based catalysts in PEM water electrolysis is its inherent high cost and required high loading (thus high cost) of about $3 \mathrm{mg} / \mathrm{cm}^{2}$. At present, as there are no convincing alternatives for $\mathrm{IrO}_{2}$ or $\mathrm{IrO}_{2}$-based catalysts as anode in PEM water electrolysis, reduction of their loading is only viable option to resolve this bottleneck. This can be achieved by two strategies, (i) enhancing the activity of $\mathrm{IrO}_{2}$ further by synthesizing it in nano-structured form and (ii) prepare $\mathrm{IrO}_{2}$ catalyst in a supported or dispersed form. Both the strategies if employed simultaneously using a simple, fast, efficient and cost-effective synthesis method can lead to reduction of overall catalyst-cost, resolving the bottleneck for commercialization of PEM water electrolysis.

\section{S1.3. Reported synthesis methods for nano-structured $\mathrm{IrO}_{2}$ and their drawbacks}

Nanostructured $\mathrm{IrO}_{2}$ have been synthesized by variety of methods, for example, metal organic chemical vapor deposition (MOCVD) method ${ }^{2}$, vapor phase transport process ${ }^{3}$, electrochemical synthesis ${ }^{4}$, arc vaporization ${ }^{5}$, hydrothermal ${ }^{6}$, reactive radio frequency magnetron sputtering (RFMS $)^{7}$, wetness method ${ }^{8}$, thermal decomposition of precursor $\left(\mathrm{H}_{2} \mathrm{IrCl}_{6}\right)^{9}$ and oleylamine-mediated synthesis ${ }^{10}$. In the last decade, the Adams fusion method ${ }^{11}$ is preferred to produce fine (nano-structured) platinum-group-metal (PGM) oxide powders and has been used widely for synthesis of iridium oxide ${ }^{12-14}$. The sol-gel method reported to yield nano-structured noble metal oxides ${ }^{15}$ while a modified polyol method was reported to produce nano-structure $\mathrm{IrO}_{2}{ }^{12,16,17}$. Most of these reported synthesis methods use the iridium chloride as precursor and are synthesized at temperatures less than $500^{\circ} \mathrm{C}$, leading to chloride impurities in the final product.

To overcome the impurity issue, a sulfite-complex route was proposed, in which iridium chloride is firstly converted to a sulfite-complex, which further precipitated as iridium hydroxide hydrate with the help of addition of hydrogen peroxide at $80^{\circ} \mathrm{C}$ and calcining it at $350^{\circ} \mathrm{C}$ to give a 'chloride-free' iridium oxide ${ }^{18,19}$. Most of these methods employ expensive, complex or unstable iridium-containing precursors followed with tedious synthetic procedures. Recent publication on molten salt synthesis process presents an alternate to above mentioned synthetic methods for $\mathrm{IrO}_{2}{ }^{20}$. Main disadvantage of these solution based methods are in their washing and thermal treatment step, where the very fine particles obtained undergo uncontrolled agglomeration and loose its dispersing ability (required for catalyst-ink preparation), leading to poor quality catalyst coatings over PEM electrolyte. Solution combustion synthesis (SCS) is a simple and fast method to produce high-surface-area oxide (dry and highly dispersible) catalysts in single step, which does not need any washing or further heat treatment. High dispersing ability of products are attributed to unique porous morphology produced by solution combustion method.

\section{S1.4. Advantage and simplicity of solution combustion synthesis (SCS)}

SCS is a combustion synthesis process, a highly exothermic and self-sustaining reaction, and has been used to synthesize a variety of compounds including binary/complex oxides ${ }^{21,22}$. As the name suggests, a precursor is used in a solution form which is usually metal nitrate (oxidizers: source of metal species) in the presence of chemical fuel such as glycine, urea, etc. (Figure S2). During SCS, development of high temperature gradient in the 
synthesis media occurs along with the production of voluminous gases which continuously escapes to atmosphere. High-temperature produced during SCS annihilates the volatile impurities in the synthesis media and often an impurity-free or low-impurity final product can be produced. A vigorous reaction at high temperatures for a short time and escaping-voluminous gases lead to the formation of oxide phase, but they also obstructs the crystallite/grain-growth in the product. Evolving gases during SCS have been known to produce porous microstructures in the final product, resulting in a high-surface-area.

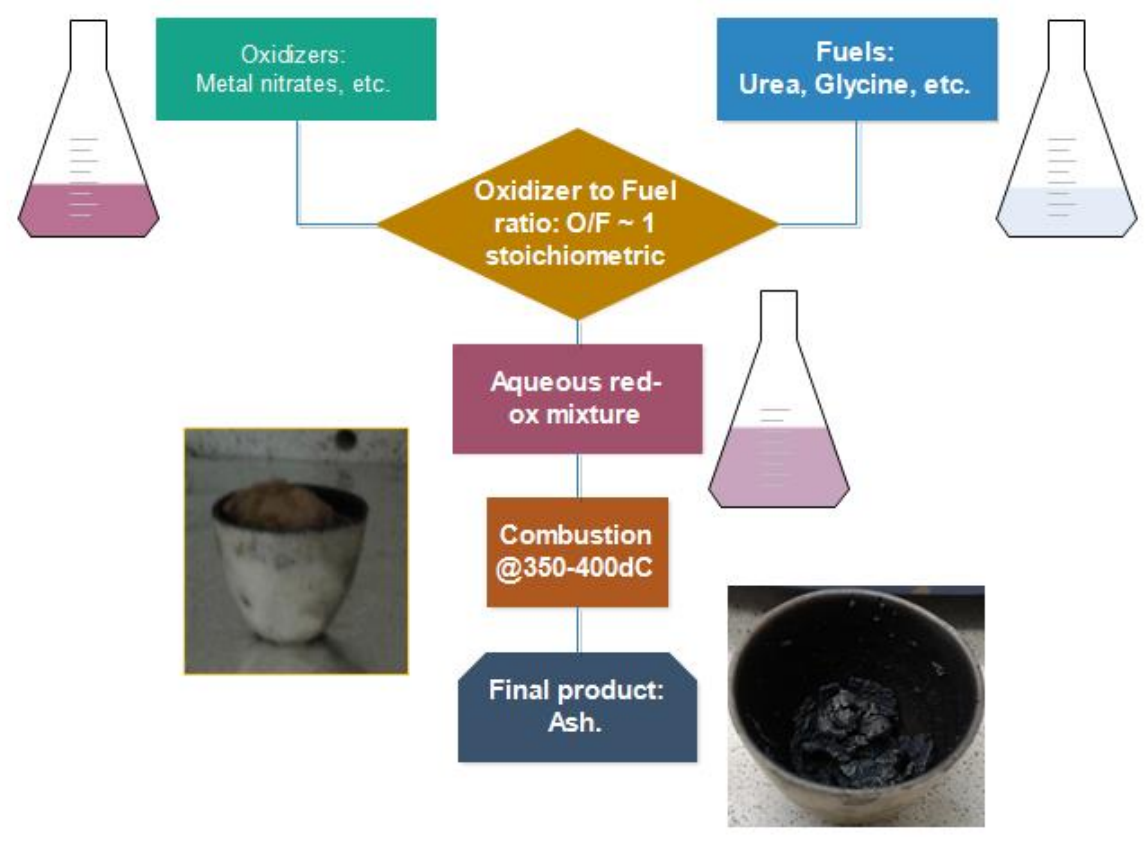

Figure S2. Simple, fast and straightforward (general) procedure to synthesize nano-structured oxides using solution combustion synthesis (SCS).

\section{S2. Experimental}

\section{S2.1. Synthesis of iridium oxide by SCS}

In general, to synthesize iridium oxide by SCS, initially, iridium chloride $\left(\mathrm{IrCl}_{3} \cdot \mathrm{X} \cdot \mathrm{H}_{2} \mathrm{O}, 99 \%\right.$, Precious Metal Online (PMO), Australia), ammonium nitrate $\left(\mathrm{NH}_{4} \cdot \mathrm{NO}_{3}\right.$, Alfa Aesar, $\left.95 \%\right)$, aluminum nitrate non-hydrate $\left(\mathrm{Al}\left(\mathrm{NO}_{3}\right)_{3} \cdot 9 \cdot \mathrm{H}_{2} \mathrm{O}, 98 \%\right.$, Fluka Analytic) and glycine $\left(\mathrm{C}_{2} \mathrm{H}_{5} \mathrm{NO}_{2}, 99.5 \%\right.$, Alfa Aesar) were separately dissolved in distilled deionized water using magnetic stirrer for at least 30 minutes. The desired precursor solution with a predetermined molar proportion of components is then mixed by stirring for 30 minutes. The solution is then transferred to an alumina crucible and placed on hot-plate kept at $80{ }^{\circ} \mathrm{C}$ with continuously stirring till the solution turned into a viscous gel. The alumina crucible with viscous-gel is then moved to a muffle-furnace, preheated at $400^{\circ} \mathrm{C}$, and kept for $2 \mathrm{~h}$. After this heat treatment, the final product in the form of black foam/ash was collected and characterized/tested, without any post-treatments or washing.

Table S1. Various molar proportion of precursor composition for the synthesis of iridium oxide using SCS and their respective sample IDs. Here, $\mathrm{M}$ are moles of iridium chloride $\left(\mathrm{IrCl}_{3}\right), \mathrm{O} 1$ are moles of ammonium nitrate, $\mathrm{O} 2$ are moles of aluminum nitrate and $\mathrm{F}$ are moles of glycine. \#\# is series designation. The $\measuredangle$ and $\nwarrow$ signifies limit for fine molar variation in IrAlG series, where iridium chloride molarity was kept fixed to one and molar proportion of 'stoichiometric oxidizer-fuel mix' was varied between 1 to 2 with step of 0.2 . The sample IrA1G1 $\equiv \operatorname{IrA1G10}$ and IrA1G2 $\equiv$ IrAlG20 (same symbol) but with different IDs for sake of continuity in variation of proportion and their analysis. Similarly, the samples IrAlG14 and IrA114G23 are the same $(\leftrightarrow$, same symbol) but with different IDs (IrAlG1.4 = $(1 \mathrm{x}$ Ir $)+1.4 \mathrm{x}(1 \mathrm{x}$ oxidizer $+1.66 \mathrm{x}$ fuel $)=\operatorname{IrA114G23)}$. Direction arrows show the direction of variation of molar proportion with reference to an optimized sample, by earlier series. Explanation on optimization criteria is mentioned in section S3.2. 


\begin{tabular}{|c|c|c|c|c|c|c|c|c|c|}
\hline \multicolumn{3}{|c|}{ Sample ID } & $\mathrm{M}$ & $\mathrm{Xx}[$ & $\mathrm{O} 1$ & $\mathrm{O} 2$ & $\mathrm{~F}$ & ] & \#\# \\
\hline \multicolumn{3}{|c|}{ IrG1 } & 1 & $1 \mathrm{x}[$ & $\ldots$ & $\ldots$ & 1 & ] & \\
\hline \multicolumn{3}{|c|}{$\mathrm{IrG} 2$} & 1 & $2 \times[$ & $\ldots$ & $\ldots$ & 1 & ] & ט \\
\hline \multicolumn{3}{|c|}{ IrG3 } & 1 & $3 \times[$ & $\ldots$ & $\ldots$ & 1 & ] & $\Xi$ \\
\hline \multicolumn{3}{|c|}{ IrG4 } & 1 & $4 \times[$ & $\ldots$ & $\ldots$ & 1 & ] & \\
\hline \multicolumn{2}{|c|}{ IrAmG1 } & $\stackrel{\ominus}{=}$ & 1 & $1 \mathrm{x}[$ & 1 & $\ldots$ & 0.2 & ] & \\
\hline \multicolumn{2}{|c|}{ IrAmG2 } & 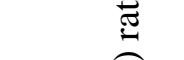 & 1 & $2 \times[$ & 1 & $\ldots$ & 0.2 & ] & U్g \\
\hline \multicolumn{2}{|c|}{ IrAmG3 } & T) & 1 & $3 \times[$ & 1 & $\ldots$ & 0.2 & ] & $\underset{\Xi}{\leftrightarrows}$ \\
\hline \multicolumn{2}{|c|}{ IrAmG4 } & $\frac{0}{0}$ & 1 & $4 \times[$ & 1 & $\ldots$ & 0.2 & ] & \\
\hline \multicolumn{2}{|c|}{ IrAlG1 $\swarrow$} & & 1 & $1 \mathrm{x}[$ & $\ldots$ & 1 & 1.66 & ] & $\vdots$ \\
\hline \multicolumn{2}{|c|}{$\mathrm{IrAlG} 2 \nwarrow$} & $\stackrel{0}{-10}$ & 1 & $2 x[$ & $\ldots$ & 1 & 1.66 & ] & $\vdots$ \\
\hline \multicolumn{2}{|c|}{ IrAlG3 } &. & 1 & $3 \times[$ & $\ldots$ & 1 & 1.66 & ] & $\vdots$ \\
\hline \multicolumn{2}{|c|}{ IrAlG4 } & प्र & 1 & $4 \times[$ & $\ldots$ & 1 & 1.66 & ] & $\vdots$ \\
\hline$\swarrow$ & IrAlG10 & $\cdot$ & 1 & $1.0 \mathrm{x}[$ & $\ldots$ & 1 & 1.66 & ] & $\vdots$ \\
\hline$\downarrow$ & IrAlG12 & $\tilde{\Xi}$ & 1 & $1.2 \mathrm{x}[$ & $\ldots$ & 1 & 1.66 & ] & ن \\
\hline$\leftrightarrow$ & IrAlG14 & $\frac{\mathscr{J}}{0}$ & 1 & $1.4 \mathrm{x}[$ & $\ldots$ & 1 & 1.66 & ] & 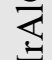 \\
\hline$\uparrow$ & IrAlG16 & 定 & 1 & $1.6 \mathrm{x}[$ & $\ldots$ & 1 & 1.66 & ] & $\vdots$ \\
\hline$\uparrow$ & IrAlG18 & D্ & 1 & $1.8 \mathrm{x}[$ & $\ldots$ & 1 & 1.66 & ] & $\vdots$ \\
\hline \multirow[t]{7}{*}{$\nwarrow$} & IrAlG 2.0 & 离 & 1 & $2.0 \mathrm{x}[$ & $\ldots$ & 1 & 1.66 & ] & $\vdots$ \\
\hline & $\begin{array}{ll}\uparrow & \mathrm{I}\end{array}$ & IrAl14G10 & 1 & $\ldots$ & $\ldots$ & 1.4 & 1.00 & $\ldots$ & $\overline{1}$ \\
\hline & $\uparrow$ & IrAl14G20 & 1 & $\ldots$ & $\ldots$ & 1.4 & 2.00 & $\ldots$ & 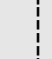 \\
\hline & $\leftrightarrow$ & IrAl14G23 & 1 & $\ldots$ & $\ldots$ & 1.4 & 2.32 & $\ldots$ & $0^{\prime}$ \\
\hline & $\downarrow$ & IrAl14G25 & 1 & $\ldots$ & $\ldots$ & 1.4 & 2.50 & $\ldots$ & $\sum_{4}^{*}$ \\
\hline & $\downarrow$ & IrAl14G30 & 1 & $\ldots$ & $\ldots$ & 1.4 & 3.00 & $\ldots$ & 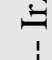 \\
\hline & $\downarrow$ & $\begin{array}{l}\text { IrAl14G35 } \\
(=\text { IrAlG) }\end{array}$ & 1 & $\ldots$ & $\ldots$ & 1.4 & 3.50 & $\ldots$ & \\
\hline
\end{tabular}

Three types of precursor compositions were investigated: (i) $\mathrm{IrCl}_{3}$ mixed with glycine in different molar proportion ( $\mathrm{IrG}$ series), (ii) $\mathrm{IrCl}_{3}$ mixed with mix of ammonium nitrate and glycine in different molar proportion (IrAmG series) and finally (iii) $\mathrm{IrCl}_{3}$ mixed with mix of aluminum nitrate and glycine in different molar proportion (IrAlG series). The oxidizer (ammonium/aluminum nitrate) and fuel (glycine) were always mixed in stoichiometric proportion. However, in case of IrAlG series, for phase pure final product the variation between oxidizer (aluminum nitrate) and fuel was varied beyond the stoichiometric proportion. Various SCSed samples were labelled according to proportion of precursor composition. For example, the sample prepared with iridium chloride and glycine in 1:4 proportion is named as IrG4, the sample prepared with iridium chloride and 'stoichiometric oxidizer-fuel mix' in 1:1 (or 1:1.4) proportion for ammonium nitrate (or aluminum nitrate) oxidizer is named as IrAmG1 (or IrAlG14), sample prepared with iridium chloride, aluminum nitrate and glycine (non-stoichiometric mix) in 1:1.4:2.0 is named as IrAl14G20 and so on. Sample IDs assigned for various composition of precursor proportion is tabulated in Error! Reference source not found.

\section{S2.2. Purely insulating alumina as support/matrix of electrocatalyst}

IrAlG series samples were expected to form $\mathrm{IrO}_{2}$ supported on or incorporated in electrically insulating alumina. Usually, the support for electrocatalyst must have a good electrical conductivity and therefore, carbon, carbon nanotube or graphene are often used as supports for electrocatalyst. But, the highly acidic atmosphere and high applied potential in anode ( $\mathrm{IrO}_{2}$ catalyst side) compartment of PEM water electrolyzer easily corrode these carbon-based supports. Literature reveals that corrosion-resistant $\mathrm{TiO}_{2}, \mathrm{SnO}_{2}$, etc., which are electrically poor conductors, were often mixed with anode catalysts in PEM water electrolyzer for improving high surface utilization 
of catalyst, provided they are mixed in proportion well below the percolation-threshold. ${ }^{16}$ The main-purpose of use of alumina as support was to improve the surface utilization of catalyst. Besides its precursor, aluminum nitrate, acted as source of nitrate in SCS.

\section{S2.3. Characterization of precursor composition and SC synthesized products}

SCS involves controlling the precursor composition (proportion of oxidizer and fuel) so that during the reaction a complete combustion would occur. This is basically achieved by balancing the oxidizing and reducing valance counts in the reactant mixture. However, in practice this ratio needs to be optimized by trail-and-errors, as many energy-losses during reaction are unaccounted in valance-balance calculations. Apart from these basic optimization strategy, in present investigation, the metal precursor is iridium chloride which is considered neutral or inadequate to provide oxidizing valance counts to proceed the SCS exothermally and therefore here an additive in the form nitrate to provide oxidizing valance counts for SCS were supplied. Effect of these additives were investigated by characterizing the precursors and their mixtures using thermo-gravimetric/differential-thermal analysis (TG-DTA, Thermogravimetric balance, Model TGA/SDTA851, Mettler Toledo). Prior to TG-DTA, the aqueous precursors or their mixtures were evaporated on hotplate till viscous gel is formed (gelation-step). These dried viscous-gel type samples were then analyzed by TG-DTA.

The SCSed products for all precursor compositions (proportions) were then characterized by X-ray diffraction (X-ray Powder Diffractometer, D8 Advance, Bruker Instruments). The X-ray diffraction (XRD) patterns were further analyzed to extract the crystallite sizes. To estimate the amount different phases i.e. the amount of iridium oxide and iridium in SCSed sample was quantified by processing the XRD patterns using Rietveld refinement technique. The samples which showed $\sim 100 \%$ iridium oxide in as-SCSed product are considered as "phase-pure SCSed iridium oxide". The phase pure SCSed iridium oxide samples were then further characterized for surface morphology and surface area using SEM (scanning electron microscope, SEM, Quanta 650 FEG, FEI)/TEM (transmission electron microscope, model 1011, JEOL) and BET (Brunauer-Emmett-Teller, autosorb $\mathrm{iQ}$, Quantachrome Instruments) isotherm technique, respectively. These phase pure SCSed materials were further used as anode catalyst in membrane electrode assemblies (MEAs) and characterized in an in-house designed electrolyzer.

\section{S2.4. MEA fabrication using SCSed products and their testing in electrolyzers}

The schematic of MEA fabrication and electrolyzer assembly is shown in Figure S3. For fabrication of the catalyst-coated-membranes (CCMs), the phase-pure SCSed iridium oxide powders as anode catalyst and 40wt\% Pt supported on carbon (platinum on graphitized carbon, 40wt\% loading, Sigma Aldrich) as cathode catalyst were spray-coated on preheated (at $80^{\circ} \mathrm{C}$ ) Nafion ${ }^{\circledR}$ membrane (Nafion ${ }^{\circledR} \mathrm{N}-115$ membrane, $0.125 \mathrm{~mm}$ thick, Alfa Aesar). Spray-coating was carried out using hand-held airbrush (Airbrush, Vulcano, Ventus). The ink for spray-coating consists of catalyst, Nafion ${ }^{\circledR}$ ionomer (Nafion® perfluorinated resin solution - 5 wt $\%$, Sigma Aldrich) and isopropanol (2-propanol, Scharlau) as solvent. For each MEA, anode and cathode catalyst loading was kept fixed at $2 \mathrm{mg} / \mathrm{cm}^{2}$ and $0.6 \mathrm{mg} / \mathrm{cm}^{2}$, respectively. Amount of Nafion ${ }^{\circledR}$ ionomer was also kept fixed for either catalyst inks and was $30 \mathrm{wt} \%$ of metal/metal-oxide catalyst loadings. All the CCMs were prepared in square shape with an active area of $4 \mathrm{~cm}^{2}$. These square shaped CCMs were then sandwiched between two titanium microporous gasdiffusion-layers (GDLs, BEKIPOR ${ }^{\circ}$ Titanium-2 GDL 28 - 0.7, Bekaert Fibre Technologies) and hot-pressed at $135^{\circ} \mathrm{C}$ for 3 min to obtain MEAs. These MEAs were then assembled in an electrolyzer-hardware, for water electrolysis evaluation. Additionally, the performance of MEA is usually suppressed by a potential drop ( $V_{\mathrm{IR}}=\mathrm{IR}$ $=$ current $\mathrm{x}$ resistance) due to the resistance of cell components and becomes noticeably high at higher current/current density. To account for such contributions, the curves were IR corrected (i.e. $\mathrm{V}_{\text {actually applied }}=\mathrm{V}_{\text {applied }}$ $\left.-\mathrm{V}_{\mathrm{IR}}\right)$.

The assembled electrolyzer was then evaluated for electrolysis performance using polarization curves, in which a voltage potential was applied to electrolyzer and respective current is measured. The applied potentials were varied from 1.2 to 2.2 volts. Application of electrical potential, acquisition of current, and data recording was perfomred using a LabVIEW (National Instruments, LabVIEW 2015) based application by controlling a digital DC power-supply (Aim and Thurlby Thandar Instruments, CPX400DP, 420 watt). Preheated $\left(80^{\circ} \mathrm{C}\right)$ mili-Q water was supplied at anode inlet of electrolyzer-hardware at fixed flow rate of $0.5 \mathrm{ml} / \mathrm{min}$. The electrolyzer cell was operated 
at $80^{\circ} \mathrm{C}$. The generated hydrogen was collected and quantified to confirm that there is no side-reaction in electrolyzer.

Furthermore, for a comparison, a commercial CCM (Electrolyzer CCM, FuelCellEtc®, USA) were also evaluated. The CCM had $\mathrm{IrRuO}_{x}$ and $\mathrm{Pt}$ as anode and cathode catalyst, respectively with catalyst loading of $3 \mathrm{mg} / \mathrm{cm}^{2}$.
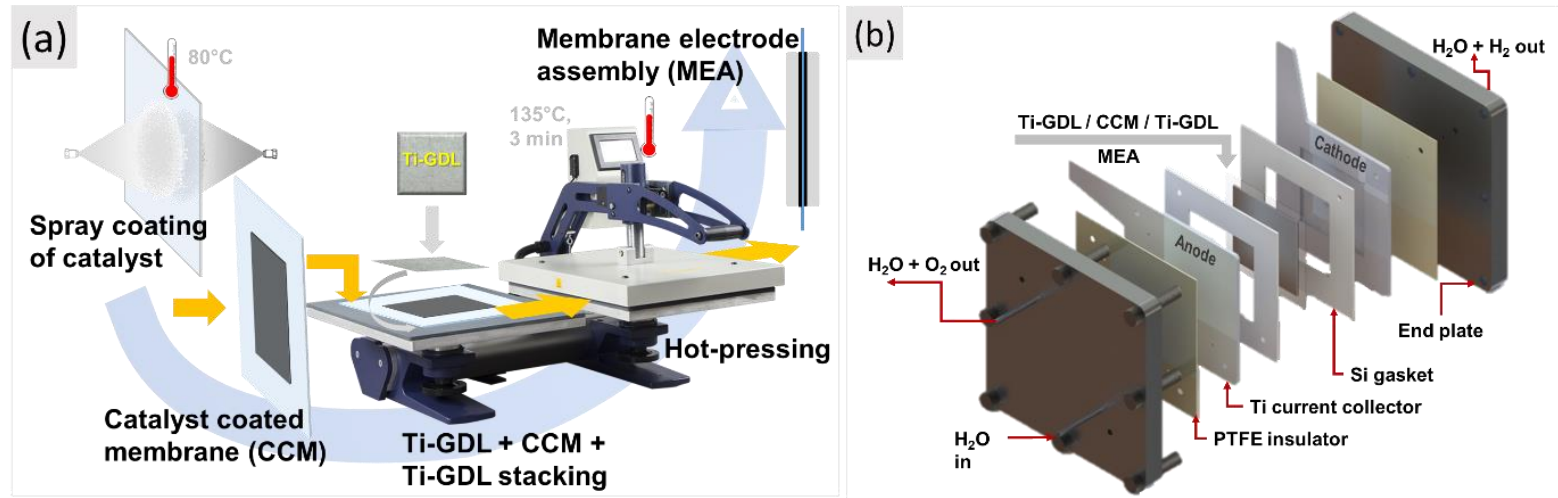

Figure S3. Schematic for (a) MEA fabrication and (b) electrolyzer assembly.

\section{S3. Results and discussion}

\section{S3.1. Thermal behavior of precursors used for SCS}

Two kinds of nitrate as oxidizer/nitrate-additive for SCS were employed, namely, ammonium nitrate and aluminum nitrate. The iridium chloride (metal precursor) and glycine were mixed in presence/absence of these nitrates and were investigated for their thermal behavior. Figure S4Error! Reference source not found. shows the TGA profiles of viscous-gel, obtained by gelation step (Section S2.1), of precursors and their mixtures. For the sake of simplicity, TGA profiles can be grouped in three groups: (I) TGA of precursors (Figure S4, a-d, solid curves), (II) TGA of nitrate and glycine in stoichiometric proportion (Figure S4, e-f; dashed curves) and (III) TGA of mixture of metal precursor and glycine (fuel) with/without oxidizer. Figure S4, g-i; dotted curves).

Up to $550^{\circ} \mathrm{C}$, glycine (Figure S4-b) does not decompose (weight loss) neither completely nor to a stableweight while iridium chloride (Error! Reference source not found., a) show a weight loss of only 10\%. However, nitrate precursors (Figure S4, c, d) decomposes completely or to a stable weight loss at temperatures less than $400{ }^{\circ} \mathrm{C}$. Ammonium nitrate (Figure S4, c) completely decomposes without any residue and can be used as residue-free oxidizer in SCS to supply additional nitrate-groups for SC reactions. This was not the case for aluminum nitrate. 


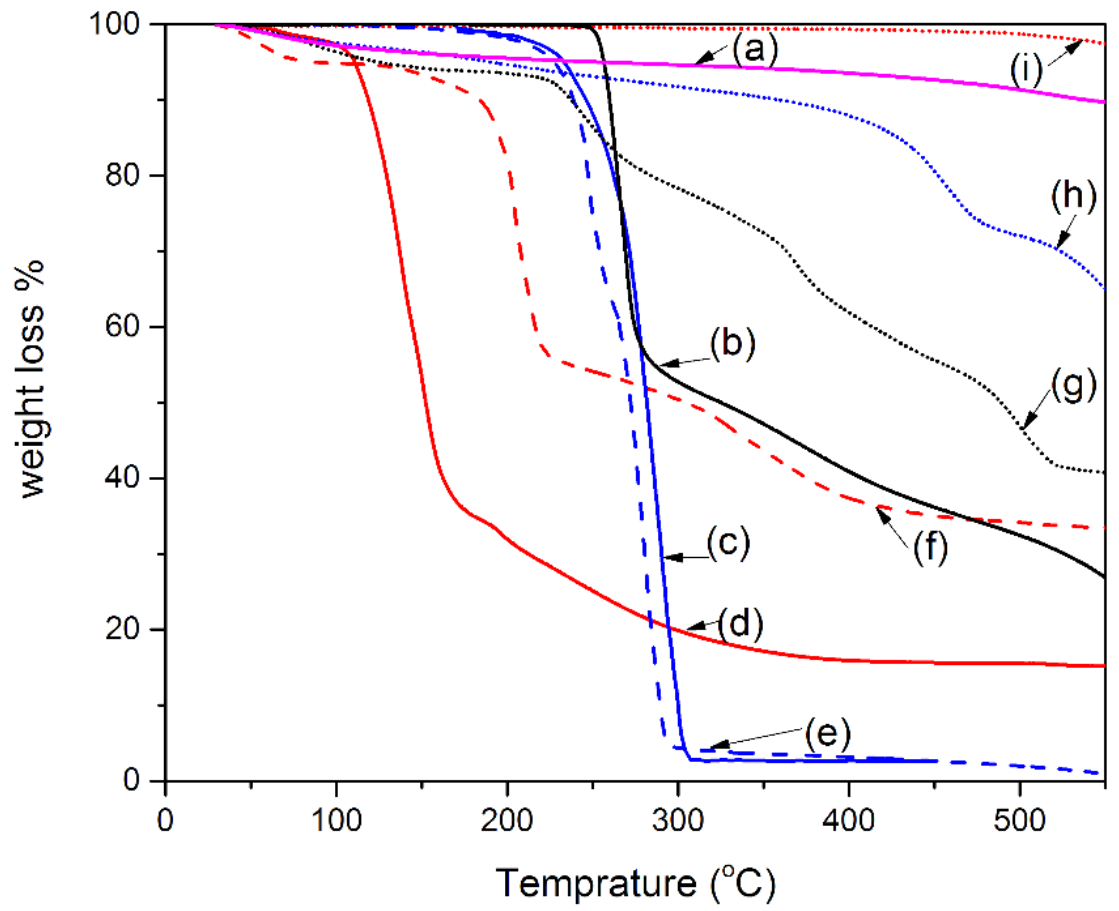

Figure S4. TGA of precursors and their mixtures, (a) iridium chloride, (b) glycine, (c) ammonium nitrate, (d) aluminum nitrate, (e) ammonium nitrate and glycine (1:0.2 = stoichiometric ratio), (f) aluminum nitrate and glycine $(1: 1.66=$ stoichiometric ratio), $(\mathrm{g})$ iridium chloride and glycine (1:1 molar proportion), $(\mathrm{h})$ iridium chloride, ammonium nitrate and glycine $(1: 1 \times(1: 0.2)=$ molar proportion with stoichiometric oxidizer/fuel mix $)$ and (i) iridium chloride, aluminum nitrate and glycine $(1: 1 \mathrm{x}(1: 1.66)=$ molar proportion with stoichiometric oxidizer/fuel mix).

TGA of nitrate mixed with glycine in stoichiometric proportion for their combustion is shown by the curves (e) and (f) in Figure S4 (dashed curves). Nitrates complexing with glycine resulted in improved thermal decomposition of nitrates. In case of ammonium nitrate (Figure S4, e), the complete and sharp decomposition onset point was seen at temperature lower than that of observed for un-mixed ammonium nitrate. For the aluminum nitrate case, the onset of decomposition was delayed and also resulted in relatively high-residue than that of observed for only aluminum nitrate. The residual-weight fraction of $33.83 \%$ ( $\pm 3 \%$ ) equals to aluminum (III) oxide weight fraction, which is SCSed upon combustion of stoichiometric mixture of aluminum nitrate and glycine (Figure S4, f). If we consider molecular weight $(\mathrm{MW})$ of reactants (nluminum nitrate +1.6 Glycine $=337.60 \mathrm{MW}$ ) as $100 \%$ and use $\mathrm{MW}$ of $\mathrm{Al}_{2} \mathrm{O}_{3}$ (= 101.96 i.e. $30.20 \%$ of reactants) then the remaining residue ( $\left.\pm 3 \%\right)$ upon SCS can be assigned to $\mathrm{Al}_{2} \mathrm{O}_{3}$. However, this can be considered as rough estimate/assignment.

TGA of iridium chloride mixed with glycine or with glycine and nitrate for their combustion is shown as curves (g), (h) and (i) in Figure S4 (dotted curves). These curves showed continuous weight loss with temperature. It might be due to the fact that the temperature ramp rate of TGA was set to $10^{\circ} \mathrm{C} / \mathrm{min}$ and the SCS was not completed in the given time span. However, in case of curve (i) in Figure S4, little and negligible weight loss was observed and attributed to the high exothermicity of reaction which occurred during gelation of this mixture and resulted in final product during gelation-step itself.

The effect of additives was clearly observed in their differential thermal analysis (DTA) curves (Figure S5). In case of oxidizer-fuel-mix (Figure S5, a, b) the exothermicity of reaction was highest while for the mixtures of metal precursors and fuel (Figure S5, c) and/or fuel-oxidizer-mix (Figure S5, d, e), was either multi-stage or relatively less. DTA of metal precursor mixed with glycine reveals multiple peaks, suggesting more than one distinct reactions. As oxide formation in SCS is generally occurs due to generated heat during reaction and therefore to obtain a phase-pure oxide of iridium in as-SCSed form, a systematic variation in mixing proportion was necessary to be designed (Error! Reference source not found.). 


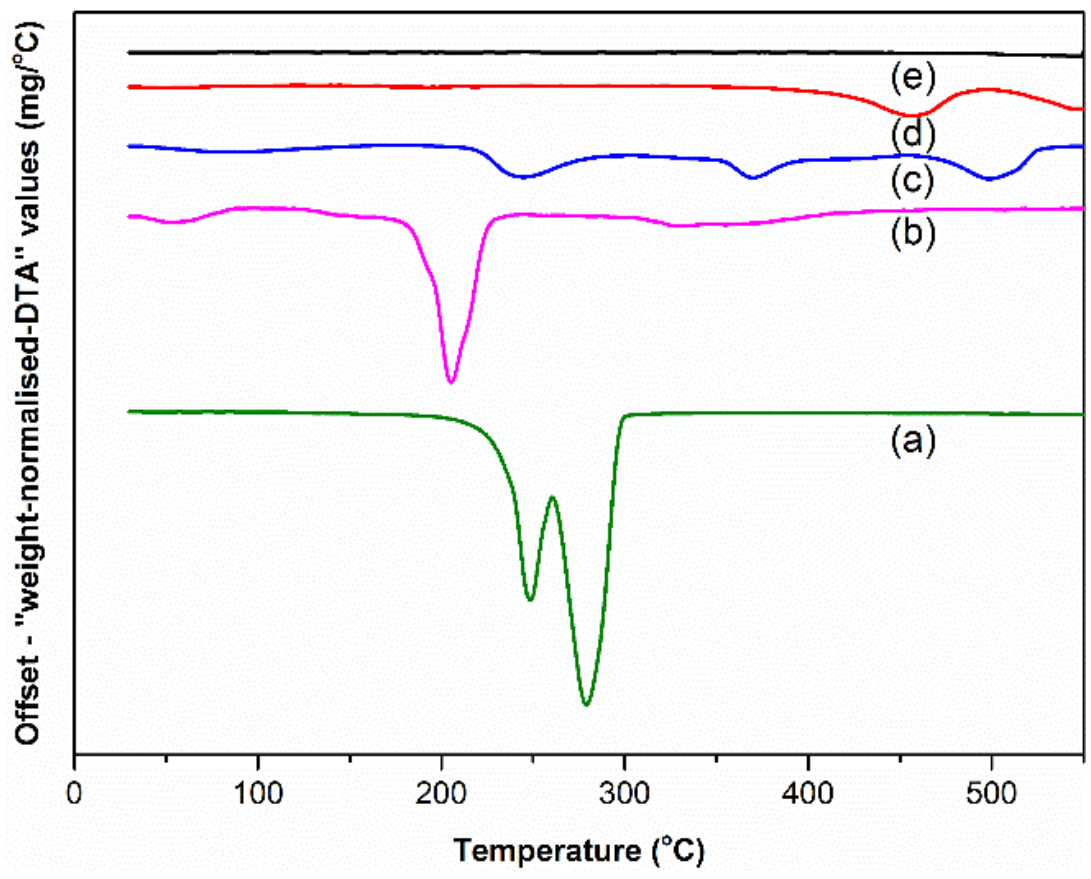

Figure S5. Weight-normalized-DTA* profiles of mixtures of precursors, (a) ammonium nitrate and glycine (1:0.2= stoichiometric ratio), (b) aluminum nitrate and glycine (1:1.66 = stoichiometric ratio), (c) iridium chloride and glycine (1:1 molar proportion), (d) iridium chloride, ammonium nitrate and glycine (1: $1 \mathrm{x}$ $(1: 0.2)=$ molar proportion with stoichiometric oxidizer/fuel mix $)$ and (e) iridium chloride, aluminum nitrate and glycine $(1: 1 \times(1: 1.66)=$ molar proportion with stoichiometric oxidizer/fuel mix $) . *$ Weightnormalized-DTA $=$ DTA-values $\div$ total weight of sample under-investigation.

\section{S3.2. Effect of variation of mixing-proportion of precursors on phase of SCSed products}

The XRD patterns of the SCSed samples prepared with varied proportion of precursors (Error! Reference source not found.)) is shown in Figure S6. All of the peaks in every XRD pattern of SCSed samples were matched with peaks corresponding to either $\mathrm{IrO}_{2}$ or metallic Ir, coinciding with the vertical lines (Figure S6) drawn referencing to the peak positions of commercial $\mathrm{IrO}_{2}$ and of commercial Ir nano-powder. The amount of phases in these XRD patterns were estimated using the Rietveld refinement technique. The crystallography information file (CIF) of $\mathrm{IrO}_{2}$ and Ir for these Rietveld refinements were retrieved from crystallography open database (COD) ${ }^{23,24}$. COD reference code for tetragonal $\mathrm{IrO}_{2}$ and cubic Ir are '96-210-1855' (COD ID: 2101855) and '96-900-8471' (COD ID: 9008471), respectively. 

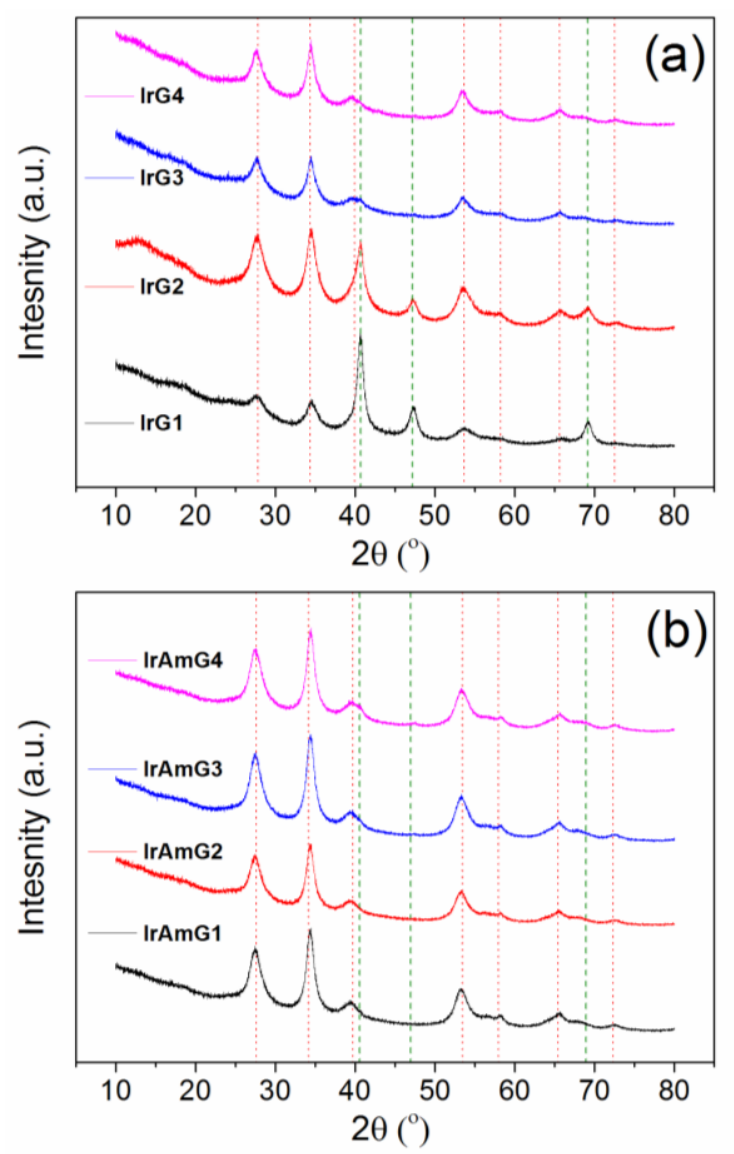

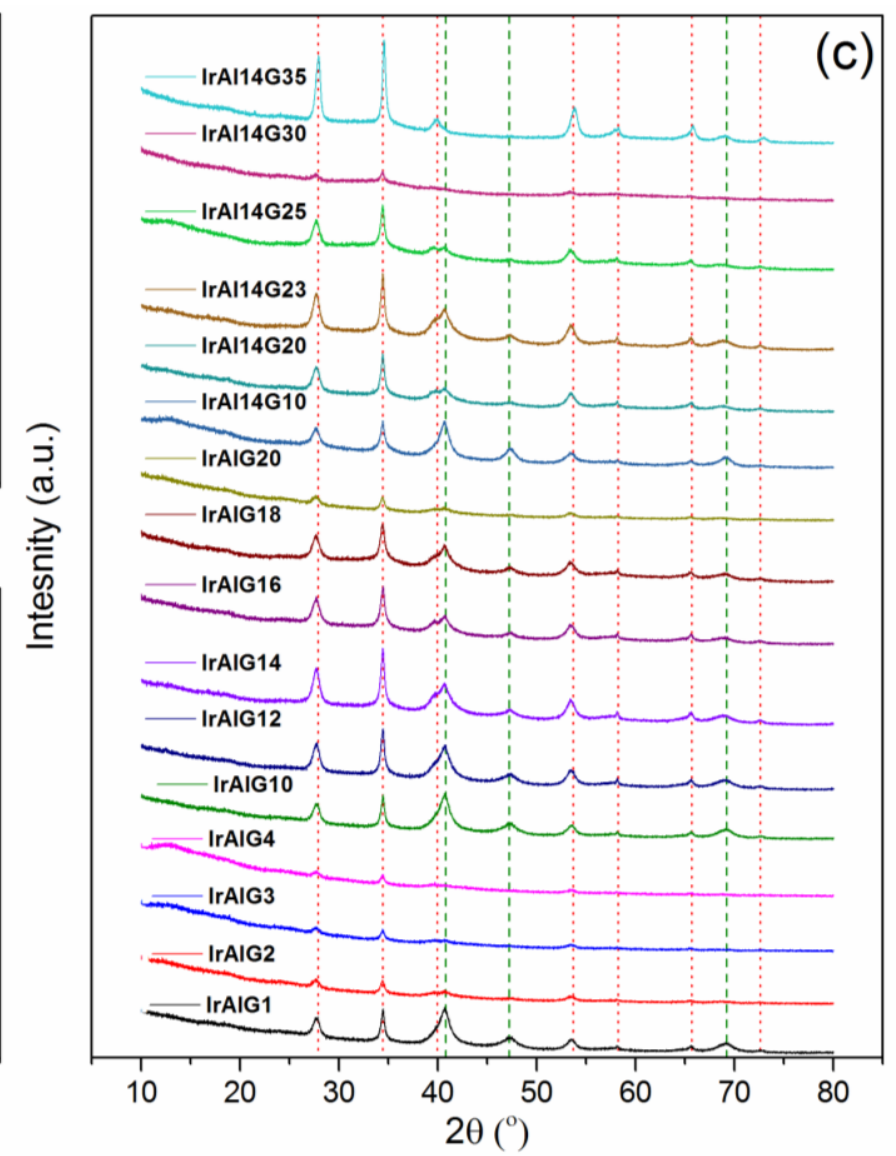

Figure S6. XRD patterns of SCSed powders: (a) IrG, (b) IrAmG and (c) IrAlG series. Details of sample IDs and the mixing proportion of precursors used to synthesize those samples are shown in Error! Reference source not found. Vertical lines in these plots correspond to peak positions of commercial $\mathrm{IrO}_{2}$ (red dotted line; …..) and of Ir-black (green - dashed line; -----) powders.

Figure S7 shows a typical Rietveld refined profile (of IrAmG4), estimated phase percentage of iridium/iridium-oxide for each of SCSed samples and their crystallite sizes. The amount iridium oxide in SCSed products (Figure S7, b) varied linearly with the amount of fuel for IrG series and with amount of stoichiometric oxidizer-fuel (OF) mix for IrAmG series. In IrG series the amount of iridium oxide increased with increased molar proportion of fuel while in IrAmG series the amount of iridium oxide decreased with increased molar proportion of stoichiometric oxidizer-fuel (OF) mix. In the earlier case, the increased proportion of fuel generated relatively higher heat producing higher amount of iridium oxide phase in SCSed products. The higher the molar proportion of stoichiometric OF mix with the same amount of iridium precursor, the higher amount of evolving gases (as ammonium nitrate decomposes totally). This may have caused an inefficient heat transfer to metal precursor, leading to decreased amount of iridium oxide in the final product. 

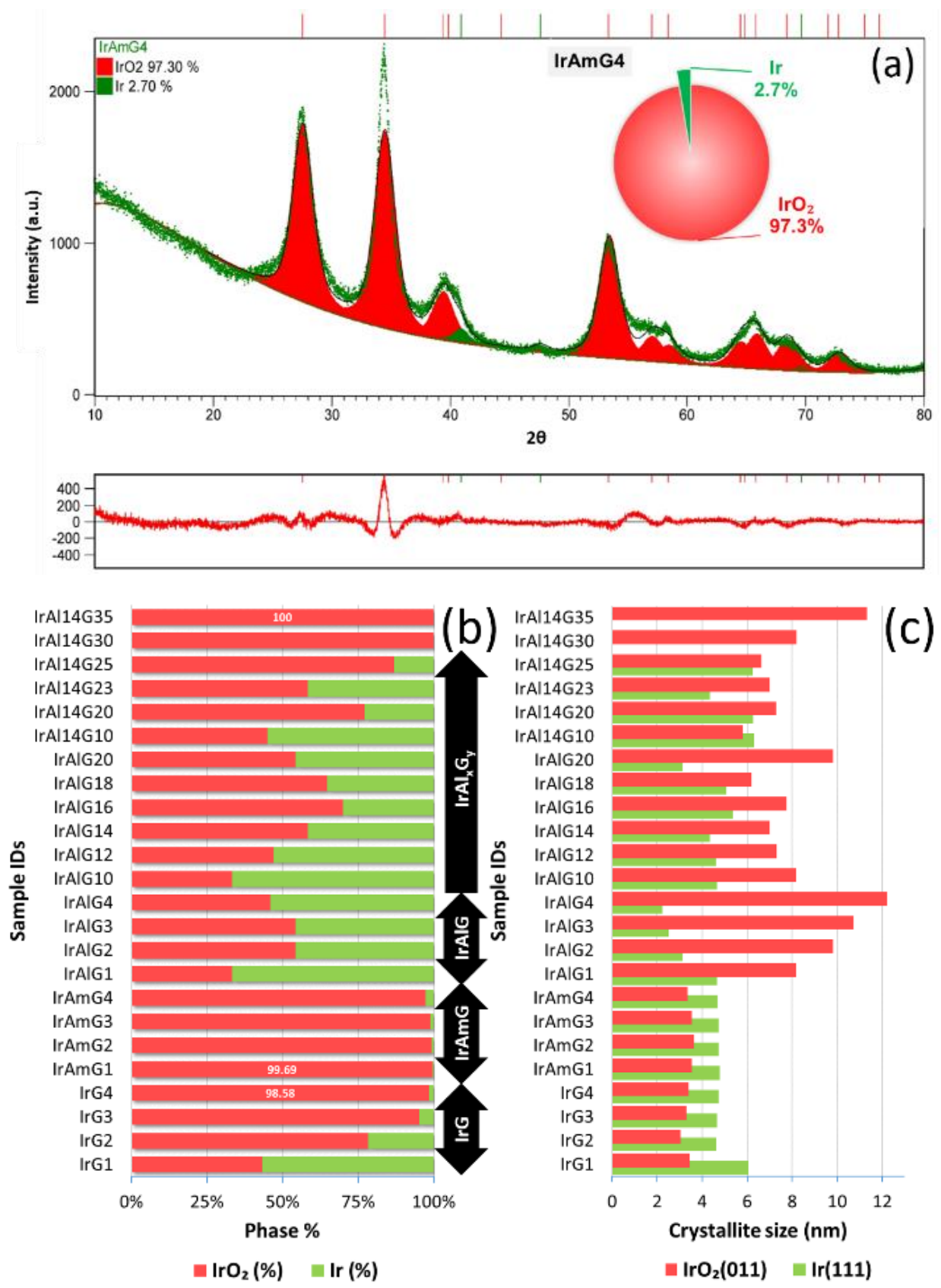

Figure S7. Results of Rietveld refinement performed on the XRD patterns of all SCSed samples. (a) Typical Rietveld refinement fitting with difference plot and estimated phase percentage for IrAmG4 sample. Estimated (b) phase \% and (c) crystallite size (nm) from the analysis fitting of XRD patterns of various SCSed samples. Details of sample IDs and the mixing proportion of precursors used to synthesize those samples are show in Error! Reference source not found.

For IrAlG series, a volcano-shape change in the amount of iridium oxide with the stoichiometric OF mix was observed (Figure S7, b). Fraction of iridium oxide was similar in the final products for 1:2 (IrAlG2 - 54.37\% $\mathrm{IrO}_{2}$ ) and 1:3 ( $\mathrm{IrAlG} 3-54.34 \% \mathrm{IrO}_{2}$ ) molar proportion of iridium chloride and stoichiometric mix of aluminum nitrate with glycine. As per the precursor mixutres in IrAlG series, upon combustion, formation of two oxides (i.e. $\mathrm{Al}_{2} \mathrm{O}_{3}$ and $\mathrm{IrO}_{2}$ ) was expected and the energy released during SCS is not enough for in-situ formation two oxides. Therefore, excess energy was provided by incorporating higher amount of fuel in precursor composition to obtain a phase pure iridium oxide on in-situ formed alumina support. Firstly, we fine-tuned the molar ratio of iridium chloride and stoichiometric oxidizer-fuel (OF) mix for IrAlG series between 1:1 and 1:2 ratios and checked for a minimal amount of stoichiometric OF mix required for clear indication of shoulder peak of iridium oxide $(2 \theta=$ 
$39.57^{\circ}$ ) in their XRD patterns. It was observed at 1:1.4 molar proportion. For further variation, the proportion of iridium chloride to aluminum nitrate was fixed to 1: 1.4 and molar proportion of glycine varied till a phase pure iridium oxide as SCSed product was obtained.

The estimated crystallite sizes of iridium oxide phase for all SCSed samples were in the range from 3.5 to $12 \mathrm{~nm}$ (Error! Reference source not found. c). A general trend of increase in crystallite size with higher amount of glycine (fuel) or stoichiometric OF mixes was observed, except for IrAmG series. In case of IrAmG series, the crystallite size is decreased with increased molar proportion of stoichiometric OF mix, which can be attributed to the inefficient heat transfer to iridium precursor, hampering further crystallite growth.

\section{S3.3. Amorphous $\gamma$-alumina as support/matrix in IrAlG sample}

Aluminum nitrate and glycine mix upon SC forms alumina according to the TGA (Section S3.1); however, the alumina peaks are not clearly visible (very broad) in the XRD pattern of IrAlG sample. Therefore, these observations indirectly suggest the formation of highly amorphous alumina (residue) during SCS has been achieved. To affirm this assumption, Raman spectra of blank support sample, i.e. AlG, was compared with Raman spectra of commercial $\alpha$ - and $\gamma$-alumina. The peaks in Raman spectra of AlG matches well with that of observed for commercial $\gamma$-alumina sample (Figure S8), suggesting the presence of $\gamma$-alumina in the blank support (AlG).

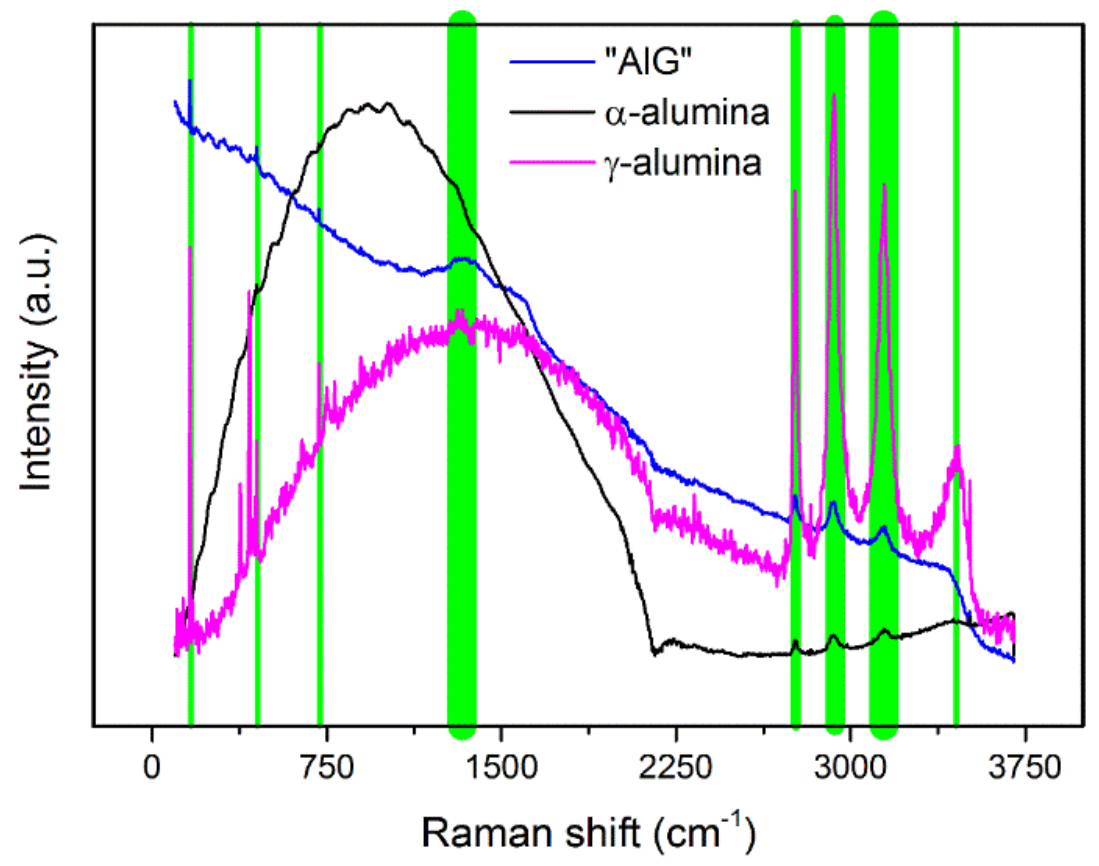

Figure S8. Raman spectra of blank support sample AlG, comparing with Raman spectra of commercial $\alpha$ - and $\gamma$ alumina. 


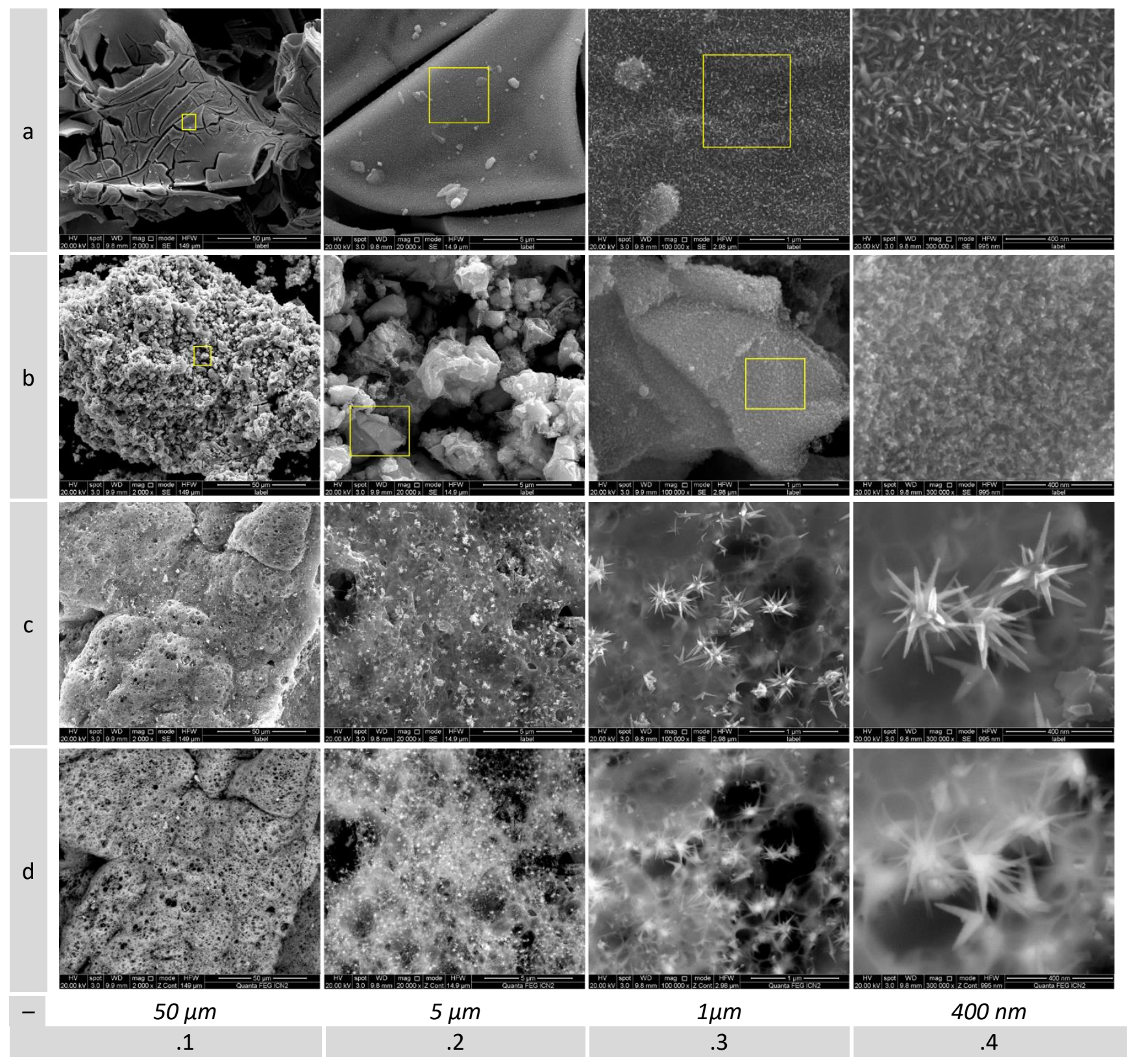

Figure S9. SEM of SCSed phase-pure iridium oxide, (a.1 - a.4) IrG4, (b.1 - b.4) IrAmG1 and (c.1 - c.4) IrAlG sample in the normal-mode (image by secondary electron). SEM image of (d.1 - d.4) IrAlG sample in the back-scattered electron mode is also shown and was taken at same area as that of taken for (c.1 c.4). 

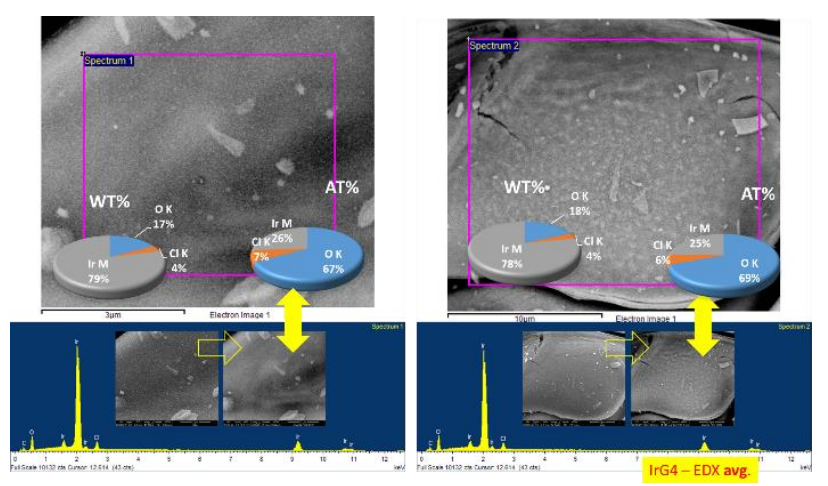

(a)
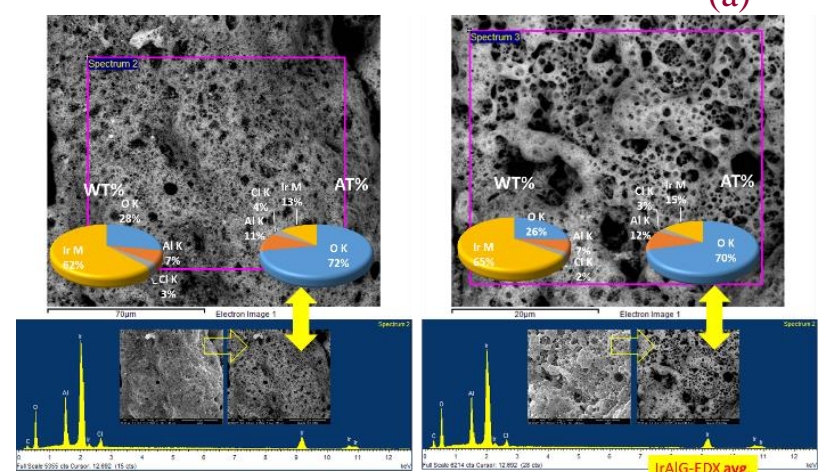

(c)
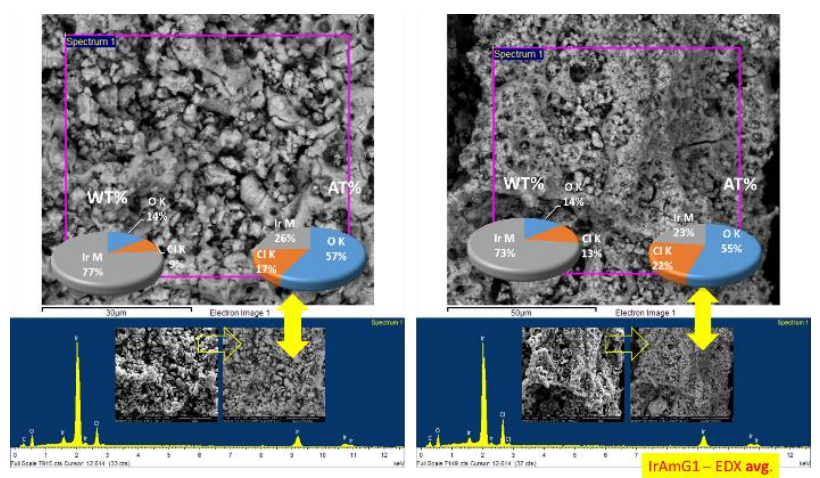

(b)

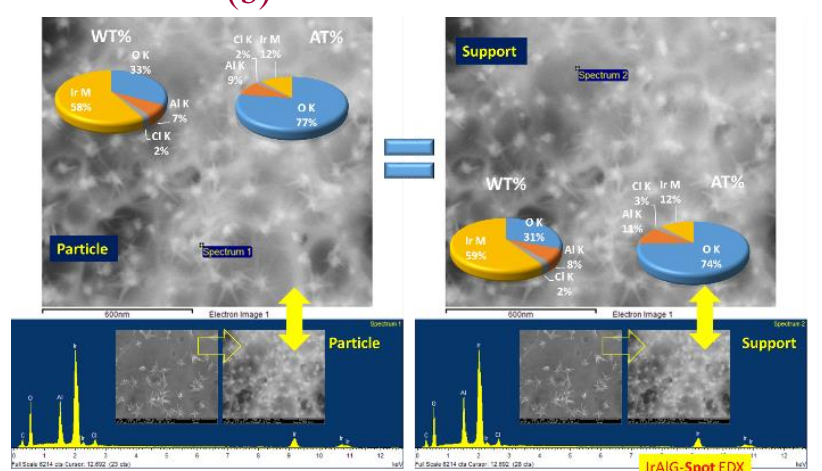

(d)

Figure S10. EDX patterns obtained at two regions of SCSed phase pure iridium oxide, (a) IrG4, (b) IrAmG1 and (c) IrAlG. (d) Spot EDX pattern obtained at needle shaped particles and particle-less area (apparently only support/matrix region) of IrAlG. Inset in each EDX pattern is the SEM image of same region (in the SE and BSE modes) for which the EDX pattern was obtained. Spot-EDX measurement reveals almost the same element-quantification for particle and support/matrix, suggesting that the identified support (from BSE image) in fact also contains iridium oxide particles hidden below the surface observed in BSE image. Furthermore, due to large difference in atomic number of two elements ( $\mathrm{Ir}$ and $\mathrm{Al}$ ) and intimate mixture of alumina and iridium oxide at sub-micron level, the adequate signal contrast/resolution for elemental mapping in SEM-EDX was not possible.

\section{S3.6. Textural properties of phase pure SCSed iridium oxide and commercial Ir nano-powder}

Table S2. Textural properties obtained from the BET isotherms of phase pure SCSed iridium oxide (IrG4, IrAmG1 and $\mathrm{IrAlG}$ ) and commercial Ir nano-powder.

\begin{tabular}{lccccc}
\hline & $\begin{array}{c}\text { External surface } \\
\text { area }\left(\mathrm{m}^{2} / \mathrm{g}\right) \\
{[\mathrm{a}]}\end{array}$ & $\begin{array}{c}\text { Micro-pore } \\
\text { area }\left(\mathrm{m}^{2} / \mathrm{g}\right) \\
{[\mathrm{b}]}\end{array}$ & $\begin{array}{c}\text { Surface Area } \\
\left(\mathrm{m}^{2} / \mathrm{g}\right) \\
{[\mathrm{c}=\mathrm{a}+\mathrm{b}]}\end{array}$ & $\begin{array}{c}\text { Average pore } \\
\text { diameter }(\mathrm{nm})\end{array}$ & $\begin{array}{c}\text { Total pore } \\
\text { volume }\left(\mathrm{cm}^{3} / \mathrm{g}\right)\end{array}$ \\
\hline IrG4 & 89 & - & 89 & 5.4 & 0.12 \\
IrAmG1 & 80 & - & 80 & 10.1 & 0.20 \\
IrAlG & 45 & 86 & 131 & 4.6 & 1.53 \\
Comm. Ir & 52 & - & 52 & 8.8 & 0.12 \\
\hline
\end{tabular}

\section{S3.7. Analysis of HR-TEM of IrAlG sample}

To extract the structural features in TEM images and their analysis (Figure S11), "ImageJ" (public domain open source software, version 1.50i) software was employed. Firstly, the images to analyze were calibrated for their scale by set scale command in ImageJ, where we proportionate the digital pixels to real world scale, i.e. $\mathrm{nm}, \mu \mathrm{m}$, etc. Later the image was further processed geometrically or for FFT. The FFT processing of the region in image 
allowed to estimate the periodicity in the image (bright spots, except center point), here the lattice planes. Those bright spots were then marked using multipoint tool of ImageJ and was further analyzed to estimate various lattice plane distances ( $d$-spacing).

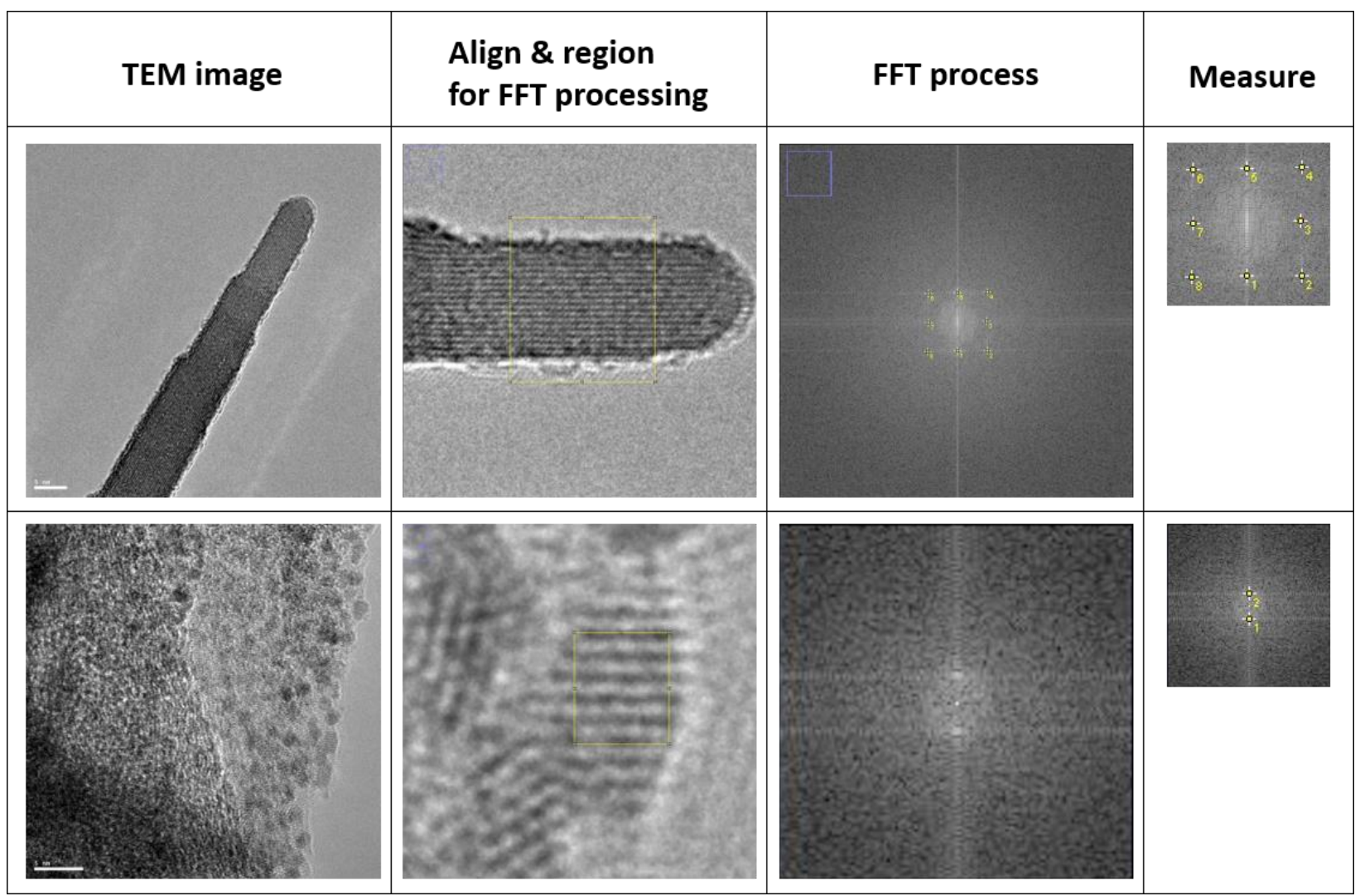

Figure S11. Analysis of TEM image of IrAlG sample. From left to right, obtained intermediate images while FFT processing using ImageJ software for needle shape structures (upper row) and for fine-nano-crystallites seen in support (lower row).

The estimated d-spacing values for nano-needle structures and nano-crystallites embedded in the support/matrix along with d-spacing values for the reference pattern is shown in Table S3. When they are compared, it is clear that the $\mathrm{d}$-spacing of the particles as well as nano-needle structures are well-matched with that of reference d-spacing values of $\mathrm{IrO}_{2}$ confirming the presence of $\mathrm{IrO}_{2}$ in the amorphous/low-crystallinity $\mathrm{Al}_{2} \mathrm{O}_{3}$. Apparently, the lattice planes of the needles seem of poly-crystalline nature, however, the most of the planes are oriented along (110) planes with d-spacing value of $0.32 \pm 0.01 \mathrm{~nm}$. 
Table S3. The d-spacing values ( $\AA$ and $\mathrm{nm}$ ) (a) for reference pattern of $\mathrm{IrO}_{2}$. The d-spacing values (nm) estimated at marked (enumerated) points on FFT processed image using ImageJ (b) for needle shape structures (upper row in Figure S11) and (c) for fine-nano-crystallites seen in support (lower row in Figure S11).

(a)

\section{COD code: 96-210-1855 (IrO)}

$2 \theta(\mathrm{deg}) \quad(\mathrm{hkl}) \mathrm{d}(\AA) \mathrm{d}(\mathrm{nm})$

$\begin{array}{llll}27.99 & (110) & 3.19 & 0.32\end{array}$

$34.65 \quad(101) \quad 2.59 \quad 0.26$

$\begin{array}{llll}40.00 & (200) & 2.25 & 0.23\end{array}$

$\begin{array}{llll}40.17 \quad(111) & 2.24 & 0.22\end{array}$

$\begin{array}{llll}44.96 & (210) & 2.01 & 0.20\end{array}$

$\begin{array}{llll}53.93 & (211) & 1.70 & 0.17\end{array}$

$\begin{array}{llll}57.85 & (220) & 1.59 & 0.16\end{array}$

$\begin{array}{llll}58.38 & (002) & 1.58 & 0.16\end{array}$

$\begin{array}{llll}65.46 & (310) & 1.42 & 0.14\end{array}$

$\begin{array}{llll}65.59 & (221) & 1.42 & 0.14\end{array}$

$\begin{array}{llll}65.96 & \text { (112) } & 1.42 & 0.14\end{array}$

$\begin{array}{llll}69.22 & (301) & 1.36 & 0.14\end{array}$

$\begin{array}{llll}72.76 & (311) & 1.30 & 0.13\end{array}$

$\begin{array}{llll}73.12 & \text { (202) } & 1.29 & 0.13\end{array}$

$\begin{array}{llll}76.12 & \text { (320) } & 1.25 & 0.12\end{array}$

$\begin{array}{llll}76.59 & \text { (212) } & 1.24 & 0.12\end{array}$

$\begin{array}{llll}83.06 & (321) & 1.16 & 0.12\end{array}$

$\begin{array}{llll}86.31 & (400) & 1.13 & 0.11\end{array}$

$\begin{array}{llll}86.76 & \text { (222) } & 1.12 & 0.11\end{array}$

\begin{tabular}{llll}
89.66 & $(410)$ & 1.09 & 0.11 \\
\hline
\end{tabular} (b)

\section{On rods}

No. d (nm) (hkl)

$10.31(110)$

$2 \quad 0.22(111)$

$3 \quad 0.32(110)$

$4 \quad 0.23(200)$

$5 \quad 0.33(110)$

$6 \quad 0.24(200)$

$7 \quad 0.32(110)$

$8 \quad 0.22(111)$ (c)

\section{Particles}

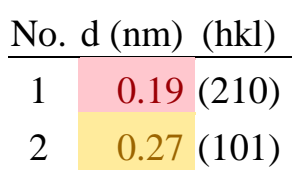




\section{S3.8. TEM of phase pure SCSed iridium oxide and commercial Ir nano-powder}

To evaluate the dispersibility of SCSed iridium oxide and commercial iridium nano-powder, they were ultra-sonicated in isopropanol (dispersant for spray-ink) for five minutes, drop-dried (for $10 \mathrm{~min}$ ) on copper mesh and analyzed using TEM (Figure S12).
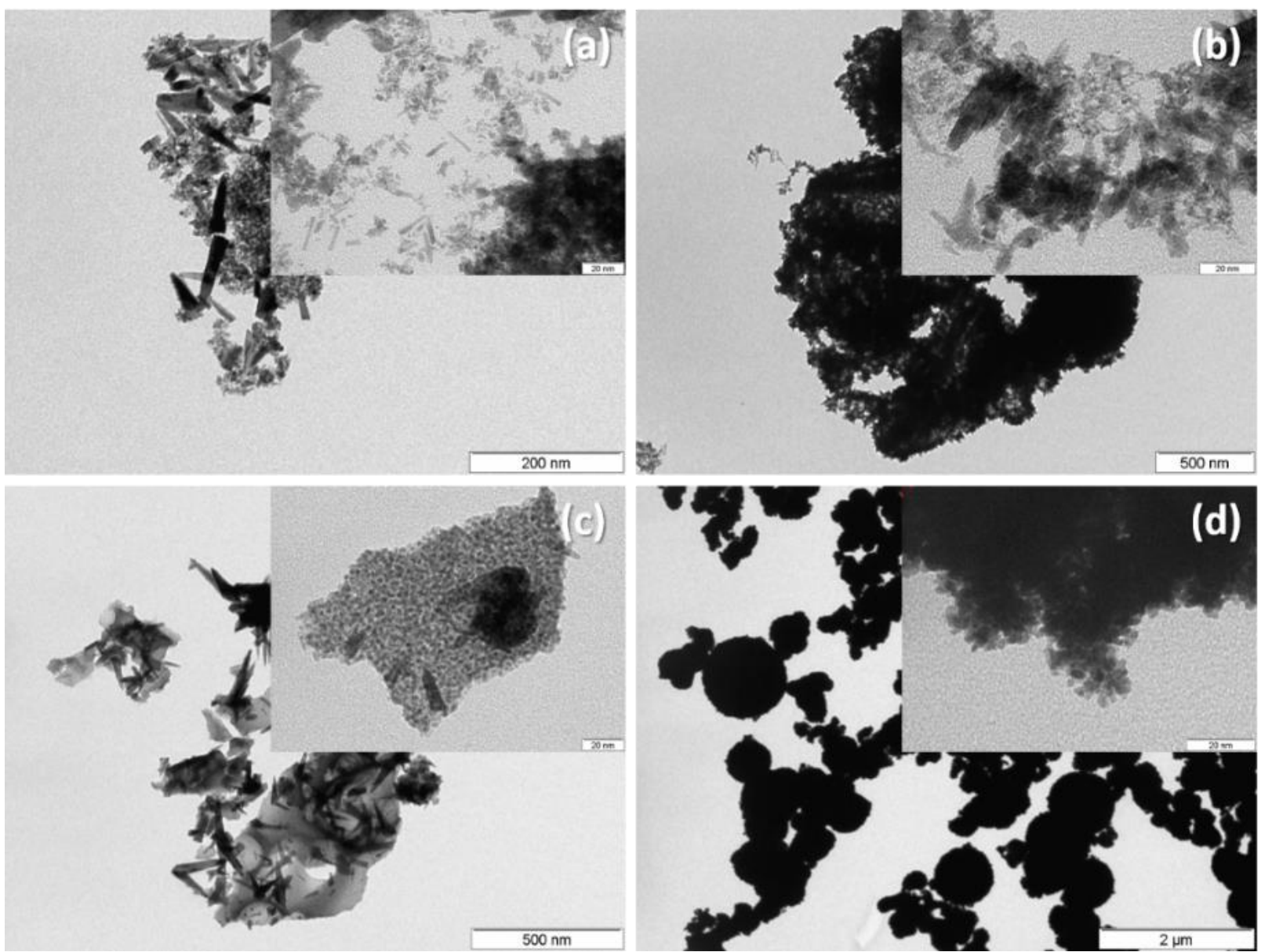

Figure S12. TEM of phase pure SCSed (a) IrG4 sample, (b) IrAmG1 sample and (c) IrAlG sample. For comparison, TEM of (d) commercial iridium nano-powder is also shown. The insets shown in each figure have the same scale-bar value $(20 \mathrm{~nm})$. 


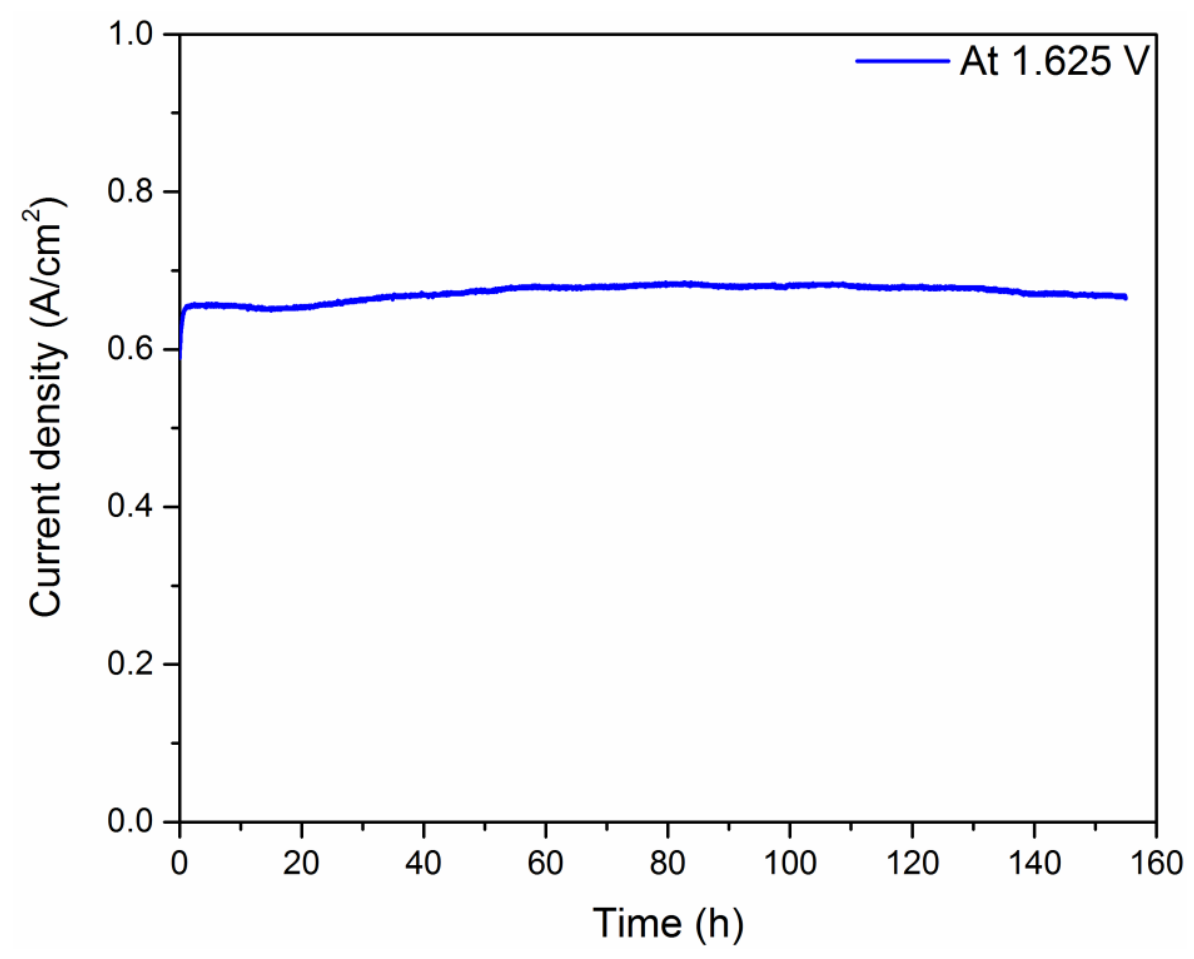

Figure S13. Stability test of IrAlG under PEM electrolysis.

The electrolyzer with IrAlG catalyst was operated to continuously work under a constant potential of 1.625 $\mathrm{V}$ for $160 \mathrm{~h}$. At this potential, the electrolyzer was initially producing current density of $0.6 \mathrm{~A} \mathrm{~cm}^{-2}$ which was raised to max. value of ca. $0.685 \mathrm{~A} \mathrm{~cm}^{-2}$ after $60 \mathrm{~h}$ of operation. The value was remained stable for another $60 \mathrm{~h}$ and started to decay slightly. At the end of $160 \mathrm{~h}$ of operation the current density of electrolyzer was about $0.635 \mathrm{~A} \mathrm{~cm}^{-}$ ${ }^{2}$, assuring the highly stable performance of IrAlG catalyst.

\section{S4. References}

1. K. Zeng and D. Zhang, Prog. Energy Combust. Sci., 2010, 36, 307-326.

2. T. W. Chao, C. J. Liu, A. H. Hsieh, H. M. Chang, Y. S. Huang and D. S. Tsai, Sensors and Actuators B: Chemical, 2007, 122, 95-100.

3. Y. Lee, M. Kang, J. H. Shim, N.-S. Lee, J. M. Baik, Y. Lee, C. Lee and M. H. Kim, The Journal of Physical Chemistry C, 2012, 116, 18550-18556.

4. C. Zhao, H. Yu, Y. Li, X. Li, L. Ding and L. Fan, J. Electroanal. Chem., 2013, 688, 269-274.

5. B. C. Satishkumar, A. Govindaraj, M. Nath and C. N. R. Rao, J. Mater. Chem., 2000, 10, 2115-2119.

6. J. Tang, B. Kong, Y. Wang, M. Xu, Y. Wang, H. Wu and G. Zheng, Nano Lett., 2013, 13, 5350-5354.

7. A. Korotcov, H. P. Hsu, Y. S. Huang and D. S. Tsai, JRSp, 2006, 37, 1411-1415.

8. J. Cheng, H. Zhang, H. Ma, H. Zhong and Y. Zou, Electrochim. Acta, 2010, 55, 1855-1861.

9. J. C. Cruz, V. Baglio, S. Siracusano, R. Ornelas, L. Ortiz-Frade, L. G. Arriaga, V. Antonucci and A. S. Aricò, J. Nanopart. Res., 2011, 13, 1639-1646.

10. Y. Lee, J. Suntivich, K. J. May, E. E. Perry and Y. Shao-Horn, The Journal of Physical Chemistry Letters, 2012, 3, 399-404.

11. R. Adams and R. L. Shriner, J. Am. Chem. Soc., 1923, 45, 2171-2179.

12. S. Song, H. Zhang, X. Ma, Z. Shao, R. T. Baker and B. Yi, Int. J. Hydrogen Energy, 2008, 33, 4955-4961.

13. J. Cheng, H. Zhang, H. Ma, H. Zhong and Y. Zou, Int. J. Hydrogen Energy, 2009, 34, 6609-6613.

14. J. Cheng, H. Zhang, G. Chen and Y. Zhang, Electrochim. Acta, 2009, 54, 6250-6256.

15. T. A. F. Lassali, J. F. C. Boodts and L. O. S. Bulhões, J. Non.Cryst. Solids, 2000, 273, 129-134. 
16. A. Marshall, B. Børresen, G. Hagen, M. Tsypkin and R. Tunold, Mater. Chem. Phys., 2005, 94, 226-232.

17. A. Marshall, B. Børresen, G. Hagen, M. Tsypkin and R. Tunold, Electrochim. Acta, 2006, 51, 3161-3167.

18. S. Siracusano, V. Baglio, A. Stassi, R. Ornelas, V. Antonucci and A. S. Aricò, Int. J. Hydrogen Energy, 2011, 36, $7822-7831$.

19. S. Siracusano, V. Baglio, A. Di Blasi, N. Briguglio, A. Stassi, R. Ornelas, E. Trifoni, V. Antonucci and A. S. Aricò, Int. J. Hydrogen Energy, 2010, 35, 5558-5568.

20. J. Ahmed and Y. Mao, Electrochim. Acta, 2016, 212, 686-693.

21. A. S. Mukasyan and P. Dinka, Int. J. Self-Propag. High-Temp Synth., 2007, 16, 23-35.

22. S. T. Aruna and A. S. Mukasyan, Curr. Opin. Solid State Mater. Sci., 2008, 12, 44-50.

23. S. Grazulis, D. Chateigner, R. T. Downs, A. F. T. Yokochi, M. Quiros, L. Lutterotti, E. Manakova, J. Butkus, P. Moeck and A. Le Bail, J. Appl. Crystallogr., 2009, 42, 726-729.

24. S. Gražulis, A. Daškevič, A. Merkys, D. Chateigner, L. Lutterotti, M. Quirós, N. R. Serebryanaya, P. Moeck, R. T. Downs and A. Le Bail, Nucleic Acids Res., 2012, 40, D420-D427. 